University of Wollongong

Research Online

Faculty of Engineering and Information

Faculty of Engineering and Information

Sciences - Papers: Part A

Sciences

$1-1-2013$

\title{
The response of axially restrained non-composite steel-concrete-steel sandwich panels due to large impact loading
}

\author{
Alex M. Remennikov \\ University of Wollongong, alexrem@uow.edu.au \\ Sih Ying Kong \\ Universiti Tenaga Nasional \\ Brian Uy \\ University Of New South Wales, brianuy@uow.edu.au
}

Follow this and additional works at: https://ro.uow.edu.au/eispapers

Part of the Engineering Commons, and the Science and Technology Studies Commons

Research Online is the open access institutional repository for the University of Wollongong. For further information contact the UOW Library: research-pubs@uow.edu.au 


\title{
The response of axially restrained non-composite steel-concrete-steel sandwich panels due to large impact loading
}

\author{
Abstract \\ In conventional steel-concrete-steel (SCS) construction, the external steel plates are connected to the \\ concrete infill by welded shear stud connectors. This paper describes a programme of experimental and \\ numerical investigations on reduced-scale non-composite SCS panels with axially restrained connections. \\ The experimental results have demonstrated that the non-composite SCS panels are capable of \\ developing enhanced load-carrying capacity through the tensile membrane resistance of the steel \\ faceplates. This type of construction was found to exhibit highly ductile response and be able to sustain \\ large end rotations of up to $18^{\circ}$ without collapse. High fidelity finite element models for SCS panels under \\ impact loading conditions were developed and the simulation results were validated against the \\ experimental data. With the validated FE models, a full-scale barrier structure composed of the non- \\ composite SCS panels and steel posts was subjected to a head-on collision by the Ford F800 single unit \\ truck. The simulation results showed that the non-composite SCS barrier construction is able to resist \\ very large impact energy and effectively terminate the fast moving vehicle. The axially restrained non- \\ composite SCS panels were found to provide an effective means for protecting assets against severe \\ impact attacks. (C) 2012 Elsevier Ltd.
}

\section{Keywords}

response, axially, loading, restrained, impact, non, sandwich, large, due, steel, panels, composite, concrete

Disciplines

Engineering | Science and Technology Studies

\section{Publication Details}

Remennikov, A. M., Kong, S. Ying. \& Uy, B. (2013). The response of axially restrained non-composite steelconcrete-steel sandwich panels due to large impact loading. Engineering Structures, 49 806-818.

This journal article is available at Research Online: https://ro.uow.edu.au/eispapers/765 


\section{The response of axially restrained non-composite steel-concrete-steel sandwich panels due to large impact loading}

Alex M. Remennikov ${ }^{1}$

Associate Professor of Structural Engineering, School of Civil, Mining and Environmental Engineering, University of Wollongong, Wollongong, NSW 2522, Australia

\section{Sih Ying Kong}

Universiti Tenaga Nasional, Malaysia

\section{Brian Uy}

Professor of Structural Engineering,

School of Engineering, University of Western Sydney, Penrith, NSW 2750, Australia

ABSTRACT: In conventional steel-concrete-steel (SCS) construction, the external steel plates are connected to the concrete infill by welded shear stud connectors. This paper describes a programme of experimental and numerical investigations on reduced-scale non-composite SCS panels with axially restrained connections. The experimental results have demonstrated that the non-composite SCS panels are capable of developing enhanced load-carrying capacity through the tensile membrane resistance of the steel faceplates. This type of construction was found to exhibit highly ductile response and be able to sustain large end rotations of up to 18 degrees without collapse. High fidelity finite element models for SCS panels under impact loading conditions were developed and the simulation results were validated against the experimental data. With the validated FE models, a full-scale barrier structure composed of the non-composite SCS panels and steel posts was subjected to a head-on collision by the Ford F800 single unit truck. The simulation results showed that the non-composite SCS barrier construction is able to resist very large impact energy and effectively terminate the fast moving vehicle. The axially

\footnotetext{
${ }^{1}$ corresponding author, tel. +612 4221 5574; fax. +61242213238.

E-mail addresses: alexrem@uow.edu.au (A. M. Remennikov),ksy965@uow.edu.au (S. Y. Kong), b.uy@uws.edu.au (B. Uy).
} 
restrained non composite SCS panels were found to provide an effective means for protecting assets against severe impact attacks. 


\section{INTRODUCTION}

Composite steel-concrete-steel (SCS) or double skin composite structures consist of a concrete core connected to two steel faceplates using mechanical shear connectors. This form of construction was originally conceived during the initial design stages for the Convy River

5 submerged tube tunnel in the UK (Narayanan [1]) and has received applications in building cores, gravity seawalls, nuclear structures and defence structures.

Shear resistance at the steel and concrete interfaces is of prime importance to achieve full composite action. Current techniques for achieving composite action include utilising mechanical shear connectors such as headed studs, friction-welded bars and J-hooks. Oduyemi and Wrigth [2], Wright et al. [3] and Shanmugam and Kumar [4] carried out experimental investigations on the response of conventional SCS structural members with headed shear studs subjected to static loading. Corus UK have developed the Bi-steel composite sandwich panels with transverse steel bars friction-welded to both steel faceplates simultaneously (Xie et al. [5]). Liew and Sohel [6] presented double J-hook connectors to interlock the steel faceplates and provide shear transfer mechanism between the steel plates and the concrete infill. Sohel and Liew [7] showed that the SCS slab developed tensile membrane action after flexural yielding under static loading condition.

SCS panels are an effective means of protecting structures against extreme impact and blast loading due to their high strength and high ductility characteristics. Young and Coyle [8] showed that Bi-steel panels were able to withstand contact and close-range detonations of high explosives without breaching failure. They also found that the required wall thickness to prevent breaching failure can be significantly reduced when Bi-steel panels are utilised in place of conventional reinforced concrete protective walls. Hulton [9] showed that full-scale barrier made 
of $300 \mathrm{~mm}$ thick Bi-steel panels can withstand explosions of 2 tonnes of explosive at a range of 2 metres. Liew et al. [10] carried out low-velocity impact tests on the J-hook panels filled with lightweight concrete. The results showed that the panels resisted the impact loading by flexural resistance with the maximum displacement of the panels being dependent on the degree of shear connection between the steel plates and the concrete infill.

Limited research has been conducted so far on the non-composite SCS sandwich panels. Heng et al. [11] carried out an experimental study on fully enclosed SCS panels under static and blast loads. Fully enclosed SCS panels in that study did not have any other means of connecting the steel faceplates and the concrete core. The model blast test results showed that this type of SCS panel can provide high level of protection and expedient construction. Lan et al. [12] carried out further experimental study on the fully enclosed SCS panels, and the results showed these panels were able to effectively resist very large explosive loads.

Crawford and Lan [13] presented the design concept of non-composite SCS panels for resisting blast loading and provided experimental verification for the full-scale blast wall. Remennikov et al. [14-15] further evaluated the concept of non-composite SCS panels and established that this form of construction provides high energy absorption capability and promising economic and technological characteristics. In this concept, the mass of concrete core provides inertial resistance, which is beneficial in resisting high-intensity impulsive loads. The imparted energy is dissipated by axial stretching of the steel faceplates and crushing of the concrete core. When the protective SCS panels are damaged, no hazardous projectiles are generated since the concrete core is confined by the steel faceplates. Additionally, the overall cost of construction is reduced by not providing shear connectors between the faceplates, thus simplifying their constructability and installation procedures. 
Based on a comprehensive literature review, it was found that no studies so far have addressed a detailed analytical and experimental investigation of the non-composite SCS sandwich panels with axially restrained connections. This study was initiated with an objective of providing an insight into the behaviour of non-composite SCS panels under extreme loading, and to formulate recommendations for design of axially restrained non-composite SCS sandwich panels as barrier structures for protection against high-speed vehicle impact and close-range detonation of high yield explosive devices. Preliminary results of axially restrained noncomposite SCS panels subjected to impact loading was reported by Remennikov et al. [14-15]. The results showed that the panels resisted the impact energy by the flexural strength at the beginning, followed by the tensile membrane action of the steel faceplates at large displacement. The flexural strength of non-composite SCS panels was lower than that of the equivalent composite SCS panels due to the lower moment of inertia of the cross-section without shear connectors. Tensile membrane action of the steel faceplates at large displacement was the main energy dissipation mechanism, where the peak tensile membrane action recorded in the test was more than $300 \mathrm{kN}$ compared to the theoretical flexural strength of the equivalent composite section of $108 \mathrm{kN}$.

This paper presents the results of experimental investigation of the response of scaled models of axially restrained non-composite SCS panels subjected to the impact of a $600 \mathrm{~kg}$ freefalling drop hammer released from a height of 3 metres. The experimental data were used for calibrating the finite element (FE) models of SCS panels using the non-linear transient dynamic finite element program LS-DYNA. Using the validated FE models, a full-scale barrier structure composed of axially restrained non-composite SCS panels has been numerically investigated in order to determine its performance under high-speed vehicle impact. 


\section{EXPERIMENTAL PROGRAMME}

Large impact energy tests were performed on four axially restrained non-composite SCS panels. The configurations of the tested panels are presented in Table 1. The Control panel had the normal weight concrete core and mild steel faceplates. For other panels, one design parameter was varied to investigate the behaviours of the non-composite SCS sandwich panels under impact loading. All the panels had the geometry and dimensions as shown in Figure 1(a). The top and bottom steel faceplates were bent into the required shape to produce flared ends using $3 \mathrm{~mm}$ steel plate. The end plates of $3 \mathrm{~mm}$ thickness were then welded to the flared ends to produce partially enclosed steel shell. The thickness of the concrete core was $80 \mathrm{~mm}$.

Specially designed keyed connections were used to connect the flared ends of the panel to the supporting structure in order to restrain axial movement of the panel during impact testing. The key inserts were formed by filling hollow trapezoid steel section with concrete, as shown in Figure 1(b). Three clearance holes for the M16 high strength bolts were prepared in the key inserts to fasten them to the steel Universal Column (UC) supporting sections, as shown in Figure 2. The UC section used was $310 \mathrm{UC} 96.8$, and the $16 \mathrm{~mm}$ mild steel gusset plates were welded to the UC section to minimise its deformation during the impact test. The UC sections were bolted to the I-beam at the bottom flanges using M25 high strength bolts and at the webs by using angle bracings. The mass of the drop hammer was approximately $600 \mathrm{~kg}$, and it was released from the height of three metres to impact the panels at the mid-span. During the experiments, the $1600 \mathrm{kN}$ capacity load cell and the high speed draw wire displacement gauge were used to record the load and displacement time histories of the panels. The National 
Instruments PXI high speed data acquisition system with sample rate of 100,000 samples/sec was used to record the experimental data.

Standard concrete cylindrical specimens were cast at the time of panel manufacturing and tested prior to the panel testing. The unconfined compressive strength of the concrete was tested in accordance with the Australian Standard AS1012.9 [16]. The Instron universal testing machine was used to obtain the material properties of mild steel and stainless steel by utilising standard coupon tests in accordance with the Australian Standard AS 1391 [17].

\section{EXPERIMENTAL RESULTS}

\subsection{Material testing}

The complete engineering stress-strain relationships for both mild steel and stainless steel faceplates are shown in Figure 3. The yield stress of mild steel was $271 \mathrm{MPa}$, whilst for stainless steel the yield stress was $291 \mathrm{MPa}$. The ultimate tensile strength of mild steel was $333 \mathrm{MPa}$, and it was $573 \mathrm{MPa}$ for stainless steel. The concrete compressive strength was different for different panels because the test specimens were prepared using different batches of concrete. For the Control and Reinforced concrete core panels, the concrete compressive strength was $23 \mathrm{MPa}$. For the Stainless steel panel, the concrete compressive strength was $37 \mathrm{MPa}$, while the concrete compressive strength for the lightweight concrete was $10 \mathrm{MPa}$.

\subsection{Impact testing of panels}

The impact load and displacement time histories for the panels are shown in Figure 4. Due to hard impact contact between the high strength steel hammer and the top steel faceplate of the panels, the load cell mounted on the drop hammer recorded high frequency noise during the test. The raw load time histories were digitally filtered using a low-pass fourth-order Butterworth 
filter in accordance with CFC1000 [18]. The cut-off frequency for the CFC1000 Butterworth filter was $1650 \mathrm{~Hz}$. From the load time histories of the axially restrained SCS panels, three distinct load resisting mechanisms can be identified and is schematically illustrated in Figure 5. These load resisting mechanisms include the inertial resistance at the initial stage of response, the flexural resistance of the sandwich panel, followed by the tensile membrane resistance of the steel faceplates. The contribution of these resisting mechanisms towards the overall performance of the non-composite SCS sandwich panels is discussed next.

\subsubsection{Inertial resistance}

The effectiveness of the barrier structures depends on the ability of the barrier components to sustain damage, but remain standing. Inertial resistance is required in addition to the strength and ductility for a structure to withstand an explosive or impact event and remain stable. Non-composite SCS sandwich panels have advantages of being relatively flexible, which act as an absorption mechanism from impact and blast loads. Additionally, by filing the SCS sandwich panels with concrete or granular materials, the panels receive a benefit of increased inertial resistance.

From the experimental load time histories, it was observed that the load increased almost instantaneously up to $1000 \mathrm{kN}$, which is more than ten times higher than the bending capacity of the panel, after the hammer came into contact with the panel. It is known that when the hammer first hits the specimen, a significant force is observed because the mass of the specimen has to be accelerated to the speed of the hammer. This inertial force peak sets the specimen and the load cell to a very rapid vibration and, therefore, the impact load measured from the load cell within the first 2 to 3 milliseconds does not represent the true flexural load acting on the specimen, as shown in Figure 4. 
After the first peak inertia force, the load time histories of the panels showed high frequency oscillations for time duration of about 5 milliseconds. Due to the impact momentum from the drop hammer, the specimen tries to fly off and the recorded force diminishes. At the same time, the panel starts to bend and the reaction forces start to appear at the supports. The bending of the panel consumes rapidly the extra kinetic energy of the impacted panel and the hammer hits the panel a second time. The load cell records the process of hitting and getting loose several times until the impact load is summed onto the actual bending load. This phenomenon has also been observed by Remennikov et al. [19]. Therefore, the force recorded in

145 the load cell at this stage represented a combination of the inertia force and flexural resistance of the panels.

\subsubsection{Flexural resistance}

The flexural capacity of the panels can be achieved after high magnitude short duration oscillations caused by the inertial effects have subsided as shown in Figure 5. The ultimate flexural capacities of the panels are presented in Table 2. It shows that the lightweight concrete core slightly reduced the ultimate flexural capacity of the panel, due to its low concrete compressive strength. The stainless steel panel showed higher ultimate flexural resistance (135 $\mathrm{kN})$ than the Control panel $(120 \mathrm{kN})$ due to non-linear strain hardening effects of the stainless steel. The higher strength of the concrete core of the Stainless steel panel $\left(f_{c}{ }^{\prime}=37 \mathrm{MPa}\right)$ compared to the Control panel $\left(\mathrm{f}_{\mathrm{c}}=23 \mathrm{MPa}\right)$ might also contributed to the higher ultimate flexural capacity. The reinforced concrete core significantly increased the ultimate flexural resistance $(205 \mathrm{kN})$ of non-composite SCS panel compared to the Control panel.

The flexural strength of all tested panels dropped significantly after the panels reached their ultimate flexural capacities. After the tests, it was observed that the concrete core of the 
Control panel, Lightweight concrete core panel and Stainless steel panel fractured, and large fragments of concrete fell out from the panel. The damage of the concrete core of these panels is exemplified by the experimental observation of the Control panel, shown in Figure 6 (a). On the other hand, the concrete core of the Reinforced concrete core panel crushed at the top and cracked at the bottom of the impact zone, as shown in Figure 6 (b). Different damage modes of the concrete core indicate that the flexural behaviour of the panels can be controlled by providing steel reinforcement to the concrete core. Figure 6 (c) illustrates the failure mode of the Lightweight concrete core panel. It can be observed that the lightweight concrete core failed in a more uniform and ductile manner compared to a brittle failure mode of the normal concrete core.

\subsubsection{Tensile membrane resistance}

From the load and displacement time histories of the sandwich panels shown in Figure 4, the tensile membrane resistance of the steel faceplates became dominant after the mid-span displacement of the panel exceeded $80 \mathrm{~mm}$ (the thickness of the panel). The peak tensile membrane resistance for each panel is shown in Table 2. It can be noticed that for the mild steel panels with different types of the concrete core, the peak tensile membrane resistance is proportional to the maximum mid-span displacement of the panel.

For the Control panel, Lightweight Core panel and Reinforced Core panel, the yield stress of the mild steel faceplates, the cross sectional area and the span of the panel are the same. Therefore, the tensile membrane resistance increased as the displacement increased. For the Stainless steel panel, it demonstrated higher peak tensile membrane resistance than the Control panel at a lower mid-span displacement. This is because the stress in the stainless steel plate increased significantly after material yielding which could be attributed to strain hardening effects. With a higher stress, the stainless steel faceplates can achieve higher tensile membrane 
resistance at lower displacement compared to the mild steel faceplate. It should be noted that the peak tensile membrane resistance obtained in these tests did not represent the tensile membrane capacity of the panels. The tensile membrane resistance could be further increased with further increase in the mid-span displacements until the steel faceplates exhibit fracture failure or axial restraint connection on the panel failed. For all the non composite SCS panels with plain concrete core investigated in this study, the tensile membrane action of the steel faceplate dissipated at least $85 \%$ of input kinetic energy.

\subsubsection{Deformation characteristics of the panels}

In this study, peak deformations of the panels were governed by the impact energy delivered by a free falling drop hammer. Since the drop height of the drop hammer was kept constant at 3 metres in all tests, the difference in the performance of the panels could be attributed to the variation in the contribution of the resistance mechanisms discussed earlier to the overall panel resistance. From analysis of the maximum displacements shown in Table 2, it is apparent that all the panels underwent very large deformation; generally, the mid-span deflections were more than twice the panel depth, without reduction in the loading carrying capacity. The support rotation of the panels exceeded 16 degrees, as shown in Table 2, proving that non-composite SCS panels can exhibit stable ductile behaviour under severe impulsive loading. Furthermore, the experimental results for the sandwich panels with the lightweight concrete core and steel mesh reinforced concrete core demonstrated that the deformation characteristics of these types of sandwich panels would vary within 10 percent of the panels with the normal unreinforced concrete core. As such, this study has concluded that variety of other infill materials such as sand, foams, mortar and granular materials can be effectively utilised for the non-composite sandwich panels. 
According to the experimental data, the panel with the steel mesh reinforced concrete core demonstrated reduction of the maximum displacement by 8 percent compared to the panel with the unreinforced concrete core. In addition, the use of stainless steel faceplates in place of the mild steel faceplates of the same thickness reduced the maximum displacement by 9 percent.

\section{VALIDATION OF FE MODELS}

The explicit dynamics non-linear finite element code LS-DYNA (Hallquist [20]) was used to numerically simulate the instrumented drop hammer tests for non-composite SCS panels. In the finite element models developed for this study, only a quarter of the experimental setup was considered due to the symmetry of the specimen, loading and support conditions, to save the computational time. The axial restraints, including the keyed inserts, bolted connections, steel UC section and steel I-beam were modelled in detail, as shown in Figure 7.

From the convergence study, a mesh size of $10 \mathrm{~mm}$ was found to be appropriate for the concrete core and the steel faceplates. Fully integrated selectively reduced (S/R) solid element formulation was used to the steel UC section, I-beam, and the bolts, while the concrete core of the panel was modelled using constant stress solid elements. The steel faceplates were modelled using Belytschko-Tsay shell elements. The Hughes-Liu with cross section integration beam elements were used to model the steel reinforcing elements.

The complete stress-strain relationships for both mild steel and stainless steel faceplates were modelled using the LS-DYNA Piecewise Linear Plasticity material model (*MAT_PIECEWISE_LINEAR_PLASTICITY). The non-linear behaviour after yielding was considered by defining plastic stress-strain relationships for both steels according to the tensile coupon test results. The strain rate effects of the mild steel and stainless steel was considered in the model by specifying the Cowper-Symonds coefficients. The Cowper-Symonds coefficients 
for mild steel are $40.4(D)$ and $5(q)$, while for the stainless steel, they are $100(D)$ and $10(q)$ (Jones [21]). The impactor was assumed absolutely rigid since there was no deformation observed on the drop hammer during the tests. The steel UC section, I-beam, bolts and wire meshes were assumed to behave as elastic perfectly plastic material and modelled using the LSDYNA Plastic Kinematic material model (*MAT_PLASTIC_KINEMATIC). The yield stress for the UC section and I-beam was assumed of $300 \mathrm{MPa}$, while the yield stress for the bolts was assumed of $600 \mathrm{MPa}$. The yield stress of the wire mesh was assumed of $450 \mathrm{MPa}$.

The Continuous Surface Cap Model 159 in LS-DYNA (*MAT_CSCM_CONCRETE) was applied to the concrete infill of the panels. This material model was developed to predict the dynamic performance of concrete structures experiencing collision by vehicles. It can generate default parameters for normal strength concrete by only requiring basic material properties like unconfined compressive strength, density, and aggregate size. According to the FHWA report [22], the model is applicable for concrete grade between $20 \mathrm{MPa}$ and $58 \mathrm{MPa}$ with the aggregate size between $8 \mathrm{~mm}$ and $32 \mathrm{~mm}$. In this study, it was found that the hourglass energy in the concrete core exceeded 50 percent of its peak internal energy when the strain rate effect was considered. The hourglass control formulations, Flanagan-Belytschko viscous form with exact volume integration for solid elements (type 3) and Flanagan-Belytschko stiffness form with exact volume integration for solid elements (type 5) were not effective to control the hourglass energy due to highly localized impact condition and large panel deformation. The hourglass energy in the concrete core can be reduced to about 15 percent of the peak internal energy when the strain rate effects are ignored. Therefore, the strain rate effect of concrete was ignored in this study to minimise the hourglass energy in the concrete core. 
The density of the lightweight concrete was $1400 \mathrm{~kg} / \mathrm{m}^{3}$ and no aggregates were used in the mix. Single element simulation (FHWA [23]) was carried out to evaluate the ability of the concrete model CSCM (*MAT_159) to generate parameters for the lightweight concrete. It was found that by using the density of $1400 \mathrm{~kg} / \mathrm{m}^{3}$, concrete compressive strength of $16 \mathrm{MPa}$ and ignoring aggregate size, the concrete model can generate a stress-strain curve with the compressive strength of $10.8 \mathrm{MPa}$ and tensile strength of $0.9 \mathrm{MPa}$, as shown in Figure 8. It was assumed that this stress-strain relationship was appropriate for the lightweight concrete used in this study. The stress-strain relationships for different grades of concrete used in this study were generated by using the single element simulations and the results are shown in Figure 8 . The stress-strain relationships included the compressive strength, tensile strength, softening curves after the concrete reached its maximum strengths.

In this study, the Automatic-Surface-to-Surface contact algorithm in LS-DYNA was used to model the contact interaction between the steel components such as the impactor-to-steel faceplates, steel faceplates-to-keyed connections, and bolts-to-support components. This contact algorithm was also used for the steel-to-concrete contact interfaces. This contact algorithm only considers the friction interaction between the steel and concrete surfaces, while the chemical bond at the steel-concrete interface was ignored in the model. This was a realistic assumption because the chemical bonding failed during the panel handling and experimental set up before the tests commenced. For the Reinforced Core panel, the nodes of the beam elements were merged with the nodes of the concrete core assuming full bond between the steel mesh and the surrounding concrete.

Numerically predicted contact forces and mid-span displacements were compared to the experimental results of the panels as presented in Figures 8 to 11. From the comparison between 
the predicted and experimental load time histories, one can notice that the numerical models were able to predict the initial flexural response of the panels followed by the tensile membrane resistance at large deformation. It shows that the numerical models have capacity to predict initial inertial effects and flexural response of the panels quite closely. After that, for the panels with an unreinforced concrete core, the FE models could not predict the significant drop in the flexural resistance due to fracture of the concrete core. For the Reinforced Core panel, the flexural strength predicted by the model was significantly higher than that in the test for times between 10 and 20 millisecond of the response. This could be attributed to modelling of the bond between the wire meshes and the concrete core by merging the nodes of the beam elements to the nodes of the concrete elements in the model. This full interaction between the concrete and the wire meshes ignored the slippage at the steel wire-concrete interface thus causing higher flexural capacity.

The FE models were also able to predict the development of the tensile membrane mechanism in the steel faceplates. The peak tensile membrane resistances from the numerical simulations are compared to the experimental results in Table 3. It shows that the predicted peak tensile membrane resistance of the panels were slightly higher than the experimental results, with the maximum difference of 8 percent. The predicted maximum mid-span displacements of the panels are compared to the experimental displacements in Figures 8 (b) to 11 (b). It shows that the models slightly underestimated the experimental displacement, and the maximum difference is 11 percent for the Lightweight Core panel, as shown in Table 3.

The models predicted similar concrete core damage for the Control panel, Lightweight Core panel, and the Stainless steel panel. The concrete core damage for these panels is exemplified by the damage contour plot for the concrete core of the Control panel, as shown in 
Figure 13. Figure 14 shows the damage contour plot of the concrete core for the Reinforced Core panel. The damage contour plot shows distribution of concrete crushing and cracking as a scalar damage parameter. As the compressive and tensile strains exceed the limiting strain for the concrete in the model, the damage parameter increases from an initial value of zero towards a maximum value of one. Concrete elements lose their strength and stiffness as the damage parameter approaches unity. For the model of the Control panel, it predicted extensive damage of the concrete core at the impact zone and near the support similar to the experimental observation, shown in Figure 6 (a). For the model of the Reinforced Core panel, the damage of the concrete core was concentrated at the impact zone similar to experimental observation shown in Figure 6 (b).

From the comparison of the numerical and test data for the impact load, maximum displacements and physical damage of the concrete, it can be concluded that the finite element model is capable of capturing the most important structural response characteristics of noncomposite SCS panel.

\section{VEHICLE CRASH ANALYSIS FOR THE FULL SCALE BARRIER STRUCTURE}

Following the validation study for the FE models of reduced scale sandwich panels, the full-scale protective barrier based on the design features presented in Figure 1 was investigated for its performance under large impact loading. One of the aims of this work was to identify potential failure mechanisms that were not brought forward during the experimental phase of this study. It should be noted that the protective barrier is different from the traffic barrier due to different in the nature of loading. The traffic barriers are used to stop and redirect vehicles in the events of accident. The traffic barriers are normally designed to be frangible so that they will undergo plastic deformation to absorb the impact energy and hence reduce the risk on passengers 
should an accident occur. The design of traffic barriers is discussed in Hui and $\mathrm{Yu}$ [24], and $\mathrm{Lu}$ and $\mathrm{Yu}$ [25]. Ferrer et al. [26] evaluated the response of parking steel columns subjected to vehicle impact at low speed by using finite element program and compared the numerical results with the design recommendations adopted in the Eurocode. Neves et al. [27] have proposed a direct method to analyse the interaction between the vehicle-structure interaction which is very efficient for large structural systems and the accuracy is comparable to the numerical simulation results.

On the other hand, the protective barriers protect targeted structures from attacks in the form of vehicle impact and also blast pressure due to detonation of high explosives. It is necessary to have a perimeter wall to reflect and dissipate impulsive energy from blast pressure. In this paper, only vehicle impact scenario on the protective barrier will be discussed. It should be noted that barriers made of composite SCS panels have high stiffness, which would significantly increase the danger to vehicle passengers upon collision. However, the barriers consisting of non-composite SCS panels have relatively lower initial flexural stiffness and undergo large plastic deformation to dissipate impact energy before the stiffness increased significantly due to tensile membrane action. The barriers with non-composite SCS panels provide better passenger protection than the barrier with conventional composite SCS panels in the event of accidental vehicle collision, and still effective in containing vehicles in terrorist attack circumstances.

The height and width of the barrier structure was selected to be $3.5 \mathrm{~m}$. The overall thickness of the panel was $200 \mathrm{~mm}$, the thickness of the steel faceplates and the concrete core was $10 \mathrm{~mm}$ and $180 \mathrm{~mm}$, respectively. The panel was connected at the flared ends to the steel posts through the keyed connections shown in Figure 1. The steel plates used to form the keyed 
connections and the steel post cross-section section had a thickness of $10 \mathrm{~mm}$. The total depth of the steel post was $500 \mathrm{~mm}$. Three segments of the barrier panels were modelled in this study. The Ford single unit truck (F800) model obtained from the National Crash Analysis Center was chosen as the test vehicle. The original mass of the F800 model is $8142 \mathrm{~kg}$ according to the National Transportation Research Center [28]. The mass of the model truck was reduced to 6800 $\mathrm{kg}$ by reducing the density of the ballast to meet K12 rating barrier testing requirement [29]. The truck was positioned at right angle to the middle span of the barrier and assigned an initial velocity of $80 \mathrm{~km} / \mathrm{h}$ as shown in Figure 15.

The concrete infill of the sandwich panels was modelled using constant stress solid elements, and the steel faceplates and the steel posts were modelled using Belytschko-Tsay shell elements in LS-DYNA. The base of the steel post was assumed fixed against translation and rotation. The material properties from the tensile coupon tests (see Figure 3) for the mild steel were applied to the steel faceplates using the LS-DYNA Piecewise Linear Plasticity material model that also included the strain rate effects. The strain rate effect of the concrete was included in the LS-DYNA CSCM_Concrete (Material 159) model, and the Hourglass control algorithm (Flanagan-Belytschko stiffness form with exact volume integration) was used to control the hourglass energy in the concrete elements.

The time histories of the impact load and the mid-height displacement for the middle barrier segment are shown in Figure 16 (a). It demonstrates that the barrier sustained the maximum impact load of $2200 \mathrm{kN}$ with the maximum displacement of $440 \mathrm{~mm}$. The truck velocity diminished from $80 \mathrm{~km} / \mathrm{h}$ to zero velocity in $0.14 \mathrm{sec}$ indicating that the vehicle was fully stopped by the barrier structure as shown in Figure 17. It was observed that the cabin of the truck underwent severe plastic deformations as shown in Figure 16 (b). A large proportion of the 
initial energy of impact, about 76 percent, was dissipated through the deformation of the truck while the barrier structure absorbed only 24 percent of the impact energy delivered by the truck.

The peak reaction force on one of the supporting posts connected to the middle barrier panel was about half of the maximum impact load as shown in Figure 18 (a). The reaction force concentrated on one side of the rear flange of the post, causing plastic rotation of the flange as shown Figure 17(b). The maximum angle of rotation of the rear flange was about 10 degrees compared to the maximum rotation of the post of 0.5 degrees. The plastic rotation deformation of the rear flange increased the gap between the keyed connection and the panel causing partial pull-out from the supports as shown in Figure 19.

Figure 19 (a) shows that the front faceplate of the middle panel experienced local plastic deformation, concentrated at the bottom half of the faceplate at the flared ends and at the centre of the plate due to the localised load impact condition. The front faceplate in contact with the truck was pushed in the direction of the impact, while the upper part of the front plate moved in the opposite direction, as can be seen in Figure 19 (b). Stretching of the bottom half of the front faceplate to contain the truck caused local yielding on the faceplate. The concrete core absorbed energy by crushing and distributed the remaining impact energy onto the rear steel faceplate. The rear faceplate developed the axial resistance through the membrane mechanism as demonstrated by the load-deformation curve in Figure 19. One can also notice the uniform displacement profile at the maximum displacement shown in Figure 18 (b) confirming that the fragments of concrete core applied uniform pressure to the rear faceplate of the panel. From the contours of plastic strain, it appears that the plastic strain in the steel plates did not exceed 0.025 , which is about ten times less than the fracture strain for the steel plate, and the panel still had sufficient reserve capacity to resist higher impact load. However, the thickness of the flange of the post 
appears to have significant effect on the performance of the sandwich panel, where large axial and rotational deformations of the keyed connection might cause failure of the protective barrier if the panel were being pulled out completely from the restraining connections. To prevent the pull-out failure mode, the details of the restraining connection shown in Figure 1 should be improved to reduce plastic rotation of the flanges by providing additional stiffening elements.

\section{CONCLUSIONS}

An extensive study on the dynamic response of non-composite steel-concrete-steel sandwich panels under impact loading condition has been undertaken. The experimental programme included investigation of the effects of concrete core density, reinforcing concrete core with steel mesh, and using stainless steel for the faceplates. Three dimensional FE models of the impact tests were generated and validated against the experimental results. Based on the modelling techniques presented, the predicted peak tensile membrane resistance and peak midspan displacements correlated well with the experimental results. Using the validated modelling techniques, a full-scale barrier structure composed of the axially restrained non-composite SCS panels was subjected to a head-on impact by the single unit truck. Some conclusions based on observations made in this research can be summarised as follows:

1. High-speed impact tests on the reduced scale axially restrained non-composite SCS panels confirmed the technical viability of this type of construction for achieving very high load-carrying capacity through the tensile membrane mechanism in the steel faceplates. The panels demonstrated high ductility and an ability to sustain large support rotations of up to 18 degrees without collapse.

2. The infill materials had minor effect on the ultimate load carrying capacity of the axially restrained non-composite SCS panels. Utilisation of lightweight concrete 
or low strength concrete as compared to the normal strength and weight concrete for the sandwich core would not significantly affect the performance at large deformation due to the prevailing contribution of the tensile membrane mechanism in the steel faceplates. The panel with reinforced concrete core showed reduced peak displacement by 8 percent compared to the panel with an unreinforced concrete core. The use of stainless steel faceplates in place of the mild steel faceplates resulted in the reduced peak displacement by 9 percent.

3. From the numerical simulation results using LS-DYNA, the full-scale barrier structure utilising axially restrained non-composite steel-concrete-steel panels was able to contain the Ford single unit truck travelling at $80 \mathrm{~km} / \mathrm{h}$. It was established that excessive deformation of the keyed connections should be avoided by providing additional stiffening elements to prevent the pull-out failure mode and allow the SCS sandwich panels to develop their full design capacity. It can be concluded that the non-composite SCS panels provide an attractive solution for the expedient construction of high-performance protective barriers to resist extreme impact and blast loadings.

\section{ACKNOWLEDGEMENT}

This research was supported under Australian Research Council's Discovery Projects funding scheme (project number DP0879733), this support is gratefully acknowledged. The authors would like to thank senior technical staffs, Mr. Alan Grant and Mr. Ian Bridge for their assistance in conducting the experiments. 


\section{REFERENCES}

435 [1] Narayanan, R., Roberts, T.M. and Naji, F.J. Design Guide for Steel-Concrete-Steel Sandwich Construction: Vol. 1: General Principles and Rules for Basic Elements, The Steel Construction Institute, UK, 1994.

[2] Oduyemi, T.O.S., and Wrigth, H.D. An experimental investigation into the behaviour of double-skin sandwich beams. Journal of Constructional Steel Research 14 (3) (1989), pp. 197220.

[3] Wright, H.D., Oduyemi, T.O.S., and Evans, H.R. The experimental behaviour of double skin composite elements. Journal of Constructional Steel Research 19 (2) (1991), pp. 97-110.

[4] Shanmugam, N.E., and Kumar, G. Behaviour of double skin composite slabs-an experimental study. Journal of Steel Structures 5 (2005), pp. 431-440.

445 [5] Xie, M., Foundoukus, N., and Chapman, J.C. Static tests on steel-concrete-steel sandwich beams. Journal of Constructional Steel Research 63 (2007), pp. 735-750.

[6] Liew, J.Y. R., and Sohel, K.M.A. Lightweight steel-concrete-steel sandwich system with Jhook connectors. Journal of Engineering Structures 31 (5) (2009), pp. 1166-1178.

[7] K.M.A. Sohel and J.Y.R Liew. Steel-concrete-steel sandwich slabs with lightweight core static performance. Journal of Engineering Structures 33 (3) (2011), pp. 981-992.

[8] Young, B., and Coyle, N. Resistance of Bi-steel to in-contact and close-proximity high explosive detonations. 17th International Symposium on Military Aspects of Blast and Shock, Lac Vegas, Nevada, USA, 2002. 
[9] Hulton, F.G. The development of Protective walls. $21^{\text {st }}$ International Symposium on Military Aspects of Blast and Shock, Jerusalem, Israel, 2010.

[10] Liew, J.Y. R., Sohel, K.M.A. and Koh, C.G. Impact tests on steel-concrete-steel sandwich beams with lightweight concrete core. Journal of Engineering Structures 31(9) (2009), pp. 20452059.

[11] Heng, L., Kennedy, L.J., and Mays, G.C. Blast resistance of fully enclosed steel-concretesteel sandwich panels. 7th International Symposium on Interaction of Effect of Munitions with Structures, Mannheim, Germany, 1995.

[12] Lan, S., Lok, T.S., and Heng, L. Composite structural panels subjected to explosive loading. Journal of Construction and Building Materials 19 (2005), pp. 387-395.

[13] Crawford, J.E., and Lan, S. Blast barrier design and Testing. 2006 Structures Congress, St Louis, Missouri, USA, 2006.

[14] Remennikov, A., Kong, S.Y., Uy, B. Static and dynamic behaviour of non-composite steelconcrete-steel protective panels under large deformation. $4^{\text {th }}$ International Conference on Steel \& Composite Structures, 23-23 July 2010, Sydney, Australia, 2010.

[15] Remennikov, A., Kong, S.Y., Uy, B. Impact resistance of non-composite axially restrained steel-concrete-steel sandwich panels. The $5^{\text {th }}$ Civil Engineering Conference in the Asian Region and Australasian Structural Engineering Conference 2010, 8-12 August 2010, Sydney, Australia, 2010.

[16] Standards Australia: Methods of testing concrete, Australian Standard: AS1210-1999. 
[17] Standards Australia: Metallic materials - Tensile testing at ambient temperature, Australian Standard: AS1391 -2007.

[18] International Organization for Standardization. Road vehicles - Measurement techniques in impact tests - Instrumentation, ISO 6487-2002.

[19] Remennikov, A., Kong, S.Y., Uy, B. The Response of Foam- and Concrete-filled Square Steel Tubes under Low Velocity Impact Loading. Journal of Performance of Constructed Facilities. Doi: 10.1061/(ASCE)CF.1943-5509.0000175

[20] Hallquist, J.O. LS-DYNA keyword user's manual, Volume 1, Version 971. Livermore Software Technology Corporation (LSTC), 2010.

[21] Jones, N. Structural Impact, Cambridge University Press, 1989.

[22] Federal Highway Administration. Evaluation of LS-DYNA concrete material model 159, 485 Publication No. FHWA-HRT-05-063, 2007.

[23] Federal Highway Administration. Users manual for LS_DYNA concrete material model 159. Publication No. FHWA-HRT-05-062, 2007.

[24] Hui, T.Y.J. and Yu, T.X. Energy absorption characteristics of scaled-down guardrail beam. Structures under shock and impact VII, WIT Press 2002.

[25] Lu, G. and Yu, T.X. Energy Absorption of Structures and Materials, Woodhead Publishing 2010.

[26] Ferrer, B., Ivorra, S., Segovia, E. and Irles, R. Tridimensional modelization of the impact of a vehicle against a metallic parking column at a low speed. Journal of Engineering Structures 32 (2010), pp. 1986-1992. 
495 [27] Neves, S.G.M., Azevedo A.F.M. and Calcada, R. A direct method for analyzing the vertical vehicle-structure interaction. Journal of Engineering Structures 34 (2012), pp. 414-420.

[28] National Transportation Research Center, F800 Single Unit Truck Model User Manual, 2005.

[29] U.S. Department of State, Diplomatic Security. Test Method for Vehicle Crash Testing of 500 Perimeter Barriers and Gates, SD-STD-02.01, Revision A, U.S. Department of State, Washington, (2003). 


\section{List of tables}

Table 1: The parameters evaluated in the impact tests for non-composite SCS panels.

Table 2: A summary of the flexural resistance, tensile membrane resistance and the maximum displacement of the panels.

Table 3: A comparison between numerically predicted results with the experimental results. 


\section{List of figures}

Figure 1: Dimension and geometry of (a) non-composite SCS panel, (b) key insert.

Figure 2: Experimental setup for SCS panels with keyed connections under impact loading.

Figure 3: Complete stress-strain relationship for mild steel and stainless steel.

Figure 4: Load and displacement time histories for (a) Control panel, (b) Lightweight panel, (c) Reinforced panel, and (d) Stainless steel panel.

Figure 5: Schematic of three load resisting mechanisms for axially restrained SCS panels under impact loading conditions.

Figure 6: Damage of the concrete core of the Control panel after the impact test (a) Control panel, (b) Reinforced panel, (c) Lightweight concrete core panel.

Figure 7: Numerical model of the experimental setup for axially restrained SCS sandwich panels using an instrumented impact testing system.

Figure 8: Stress-strain relationships numerically generated for concrete infill.

Figure 9: A comparison between experimental and predicted results for the Control panel (a) load time histories, (b) displacement time histories.

Figure 10: A comparison between experimental and predicted results for the Lightweight panel (a) load time histories, (b) displacement time histories.

Figure 11: A comparison between experimental and predicted results for the Reinforced panel (a) load time histories, (b) displacement time histories.

(a) load time histories, (b) displacement time histories. 
Figure 13: Damage contour plot for the concrete core of the FE model for the Control panel.

Figure 14: Damage contour plot for the concrete core for the FE model of the Reinforced panel.

Figure 15: FE model of full scale barrier subjected vehicle impact.

Figure 16: The simulation results (a) impact force and displacement time histories for the barrier, (b) deformation of the cabin on the truck.

Figure 17: The simulation results (a) load and displacement time histories, (b) the deformation of the barrier from top view.

Figure 18: Plastic strain contour plot (a) front faceplate of the panel, (b) rear face of the steel 565 post.

Figure 19: Tensile membrane resistance provided by the rear faceplate. 
Table 1: The parameters evaluated in the impact tests for non-composite SCS panels.

\begin{tabular}{|c|c|c|c|c|}
\hline No & Panel & Parameters & $\begin{array}{l}\text { Yield stress } \\
\text { of steel } \\
\text { faceplates } \\
(\mathrm{MPa})\end{array}$ & $\begin{array}{l}\text { Concrete infill } \\
\text { compressive } \\
\text { strength (MPa) }\end{array}$ \\
\hline 1 & $\begin{array}{l}\text { Control panel } \\
\text { (CP) }\end{array}$ & $\begin{array}{l}\text { - mid steel faceplates }(3 \mathrm{~mm}) \\
\text { - normal weight concrete core }\end{array}$ & 271 & 23 \\
\hline 2 & $\begin{array}{l}\text { Stainless } \\
\text { steel panel } \\
\text { (SP) }\end{array}$ & $\begin{array}{l}\text { - stainless steel faceplates }(3 \mathrm{~mm}) \\
\text { - normal weight concrete core }\end{array}$ & 291 & 37 \\
\hline 3 & $\begin{array}{l}\text { Lightweight } \\
\text { concrete core } \\
\text { panel (LP) }\end{array}$ & $\begin{array}{l}\text { - mid steel faceplates }(3 \mathrm{~mm}) \\
\text { - lightweight concrete core }(1400 \\
\left.\mathrm{kg} / \mathrm{m}^{3}\right)\end{array}$ & 271 & 10.5 \\
\hline 4 & $\begin{array}{l}\text { Reinforced } \\
\text { concrete core } \\
\text { panel (RP) }\end{array}$ & $\begin{array}{l}\text { - } \text { mid steel faceplates }(3 \mathrm{~mm}) \\
\text { - normal weight concrete core } \\
\text { reinforced with two layers of } 4 @ 50 \\
\text { mm wire meshes. }\end{array}$ & 271 & 23 \\
\hline
\end{tabular}

Table 2: A summary of the flexural resistance, tensile membrane resistance and maximum displacements of the SCS panels.

\begin{tabular}{|c|c|c|c|c|c|}
\hline Panel & $\begin{array}{c}\text { Ultimate } \\
\text { flexural } \\
\text { resistance } \\
(\mathrm{kN})\end{array}$ & $\begin{array}{c}\text { Peak tensile } \\
\text { membrane } \\
\text { resistance } \\
(\mathrm{kN})\end{array}$ & $\begin{array}{c}\text { Maximum } \\
\text { displacement } \\
(\mathrm{mm})\end{array}$ & $\begin{array}{c}\text { Support } \\
\text { rotation }\left(^{\circ}\right)\end{array}$ & $\begin{array}{c}\text { Ratio (Max. } \\
\text { Displ./Max. } \\
\text { Displ. of the } \\
\text { Control panel) }\end{array}$ \\
\hline $\begin{array}{c}\text { Control panel } \\
(\mathrm{CP})\end{array}$ & 120 & 356 & 200 & 18 & 1 \\
\hline $\begin{array}{c}\text { Lightweight } \\
\text { core panel (LP) }\end{array}$ & 84 & 333 & 196 & 17 & 0.98 \\
\hline $\begin{array}{c}\text { Reinforced core } \\
\text { panel (RP) }\end{array}$ & 205 & 284 & 183 & 16 & 0.92 \\
\hline $\begin{array}{c}\text { Stainless steel } \\
\text { panel (SP) }\end{array}$ & 135 & 377 & 181 & 16 & 0.91 \\
\hline
\end{tabular}


Table 3: A comparison between numerically predicted results with the experimental results.

\begin{tabular}{|c|c|c|c|c|c|c|}
\hline Panel & $\begin{array}{c}\text { EXP. } \\
\text { peak } \\
\text { TMR } \\
(\mathrm{kN})\end{array}$ & $\begin{array}{c}\text { FE peak } \\
\text { TMR } \\
(\mathrm{kN})\end{array}$ & $\begin{array}{c}\text { (FE/EXP) } \\
\text { TMR }\end{array}$ & $\begin{array}{c}\text { EXP. } \\
\text { Max. } \\
\text { Displ. } \\
(\mathrm{mm})\end{array}$ & $\begin{array}{c}\text { FE. Max. } \\
\text { Displ. } \\
(\mathrm{mm})\end{array}$ & $\begin{array}{c}\text { (FE/EXP) } \\
\text { Max. } \\
\text { Displ. }\end{array}$ \\
\hline $\begin{array}{c}\text { Control } \\
\text { panel }\end{array}$ & 356 & 384 & 1.08 & 200 & 182 & 0.91 \\
\hline $\begin{array}{c}\text { Lightweight } \\
\text { core panel }\end{array}$ & 333 & 358 & 1.08 & 196 & 174 & 0.89 \\
\hline $\begin{array}{c}\text { Stainless } \\
\text { steel panel }\end{array}$ & 377 & 380 & 1.01 & 181 & 162 & 0.90 \\
\hline $\begin{array}{c}\text { Reinforced } \\
\text { core panel }\end{array}$ & 284 & 294 & 1.04 & 183 & 168 & 0.92 \\
\hline
\end{tabular}




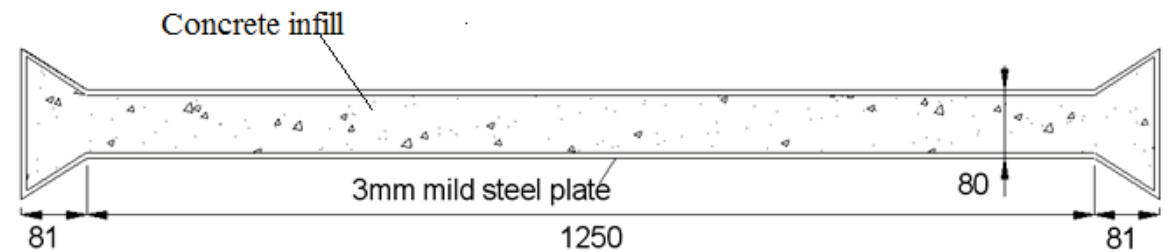

a) Steel panel

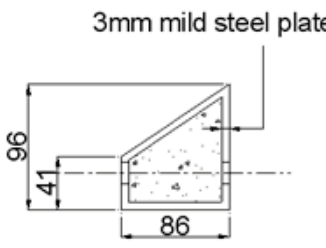

b) key insert

Figure 1: Dimension and geometry of (a) non-composite SCS panel, (b) key insert.

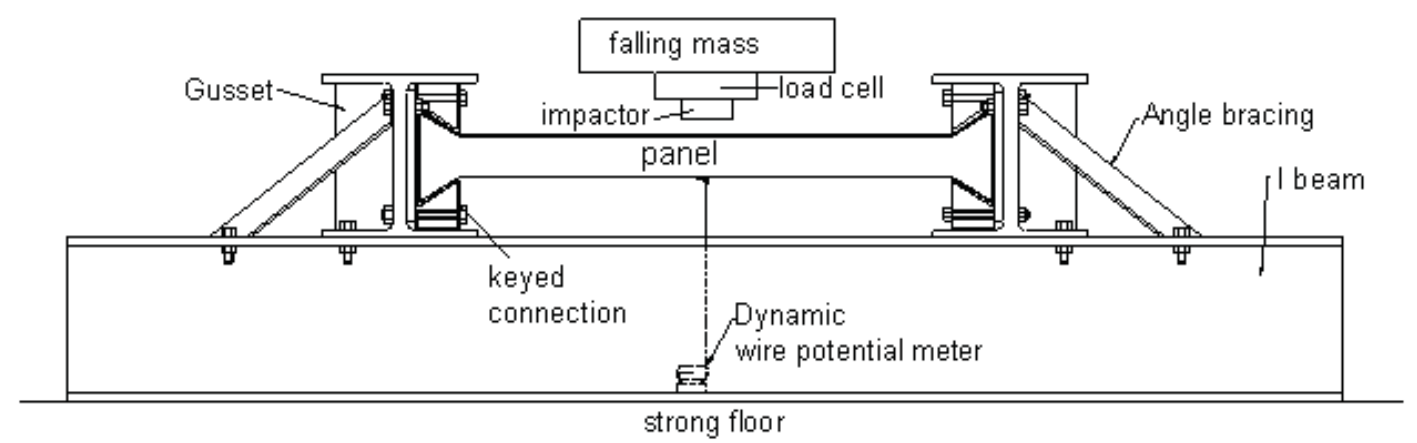

Figure 2: Experimental setup for SCS panels with keyed connections under impact loading.

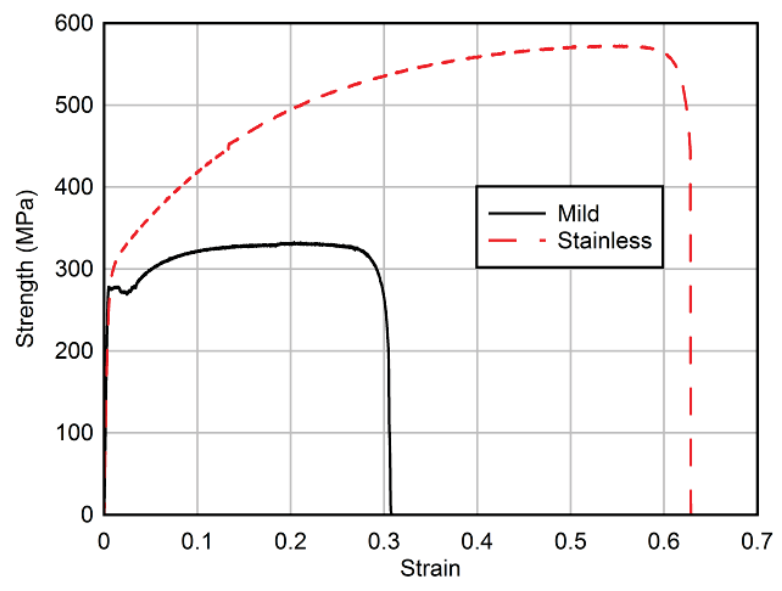

Figure 3: Complete stress-strain relationship for mild steel and stainless steel. 

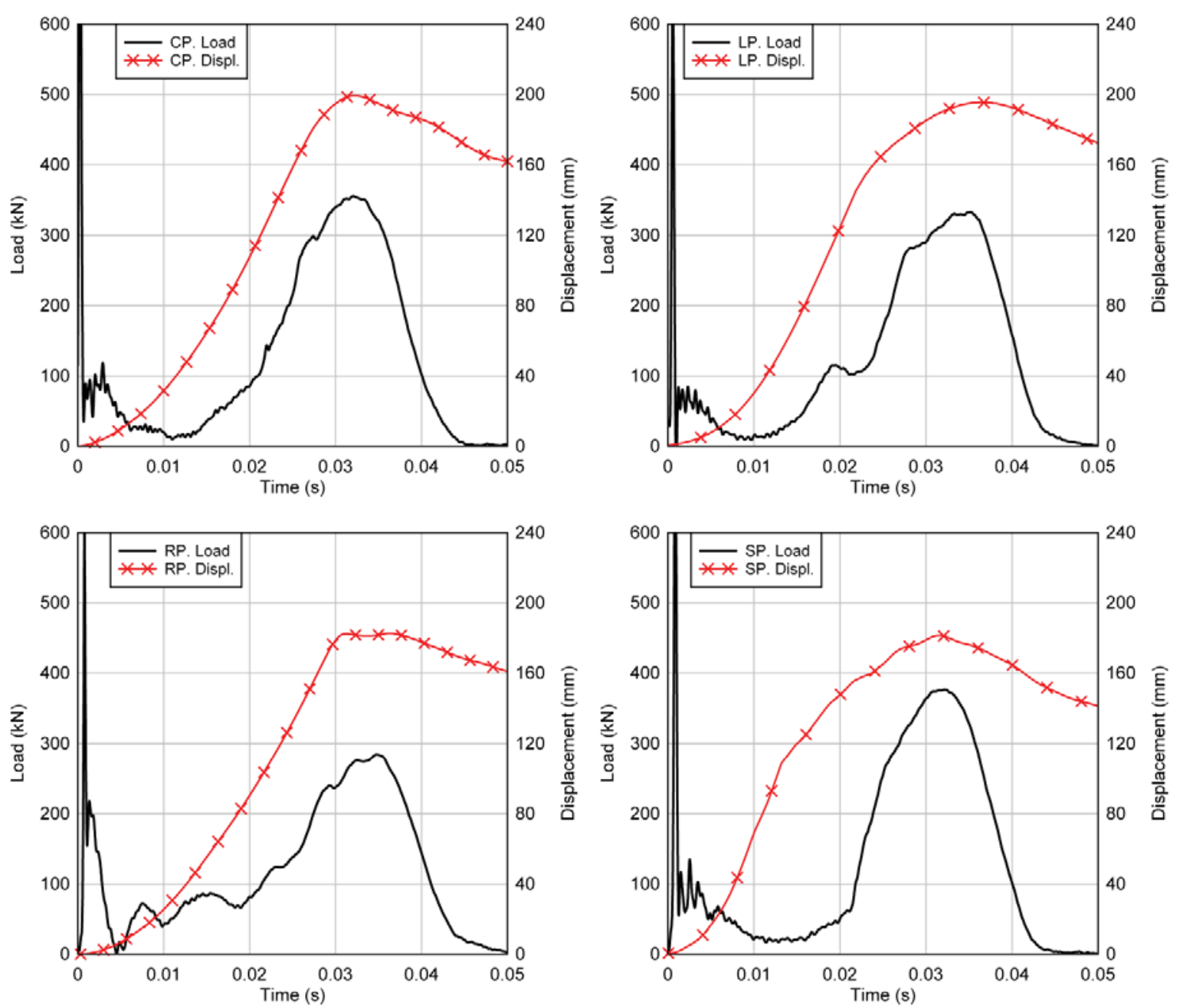

Figure 4: Load and displacement time histories for (a) Control panel, (b) Lightweight core panel, (c) Reinforced core panel, and (d) Stainless steel panel. 


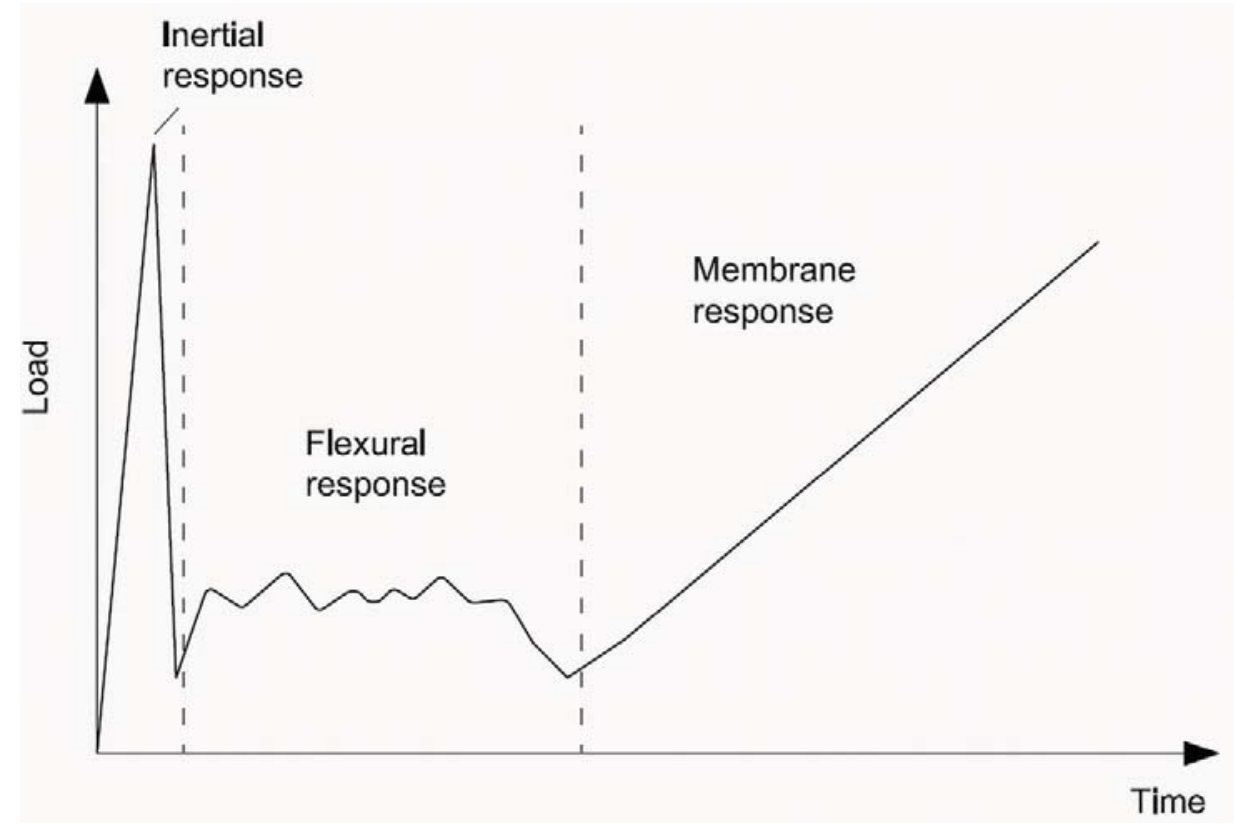

Figure 5: Schematic of three load resisting mechanisms for axially restrained SCS panels under impact loading conditions.

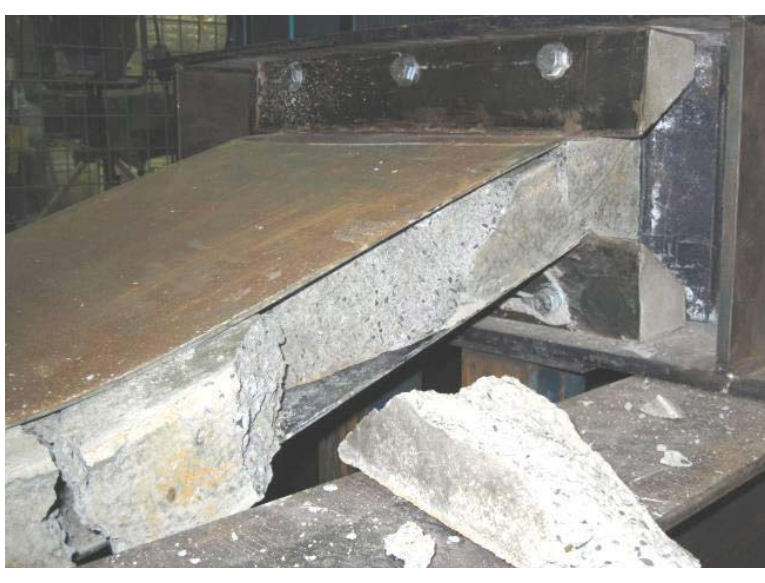

(a)

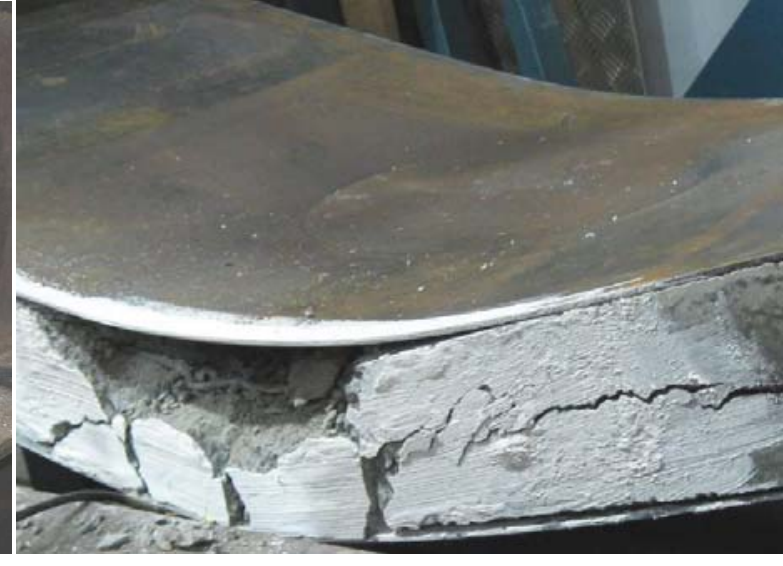

(b) 


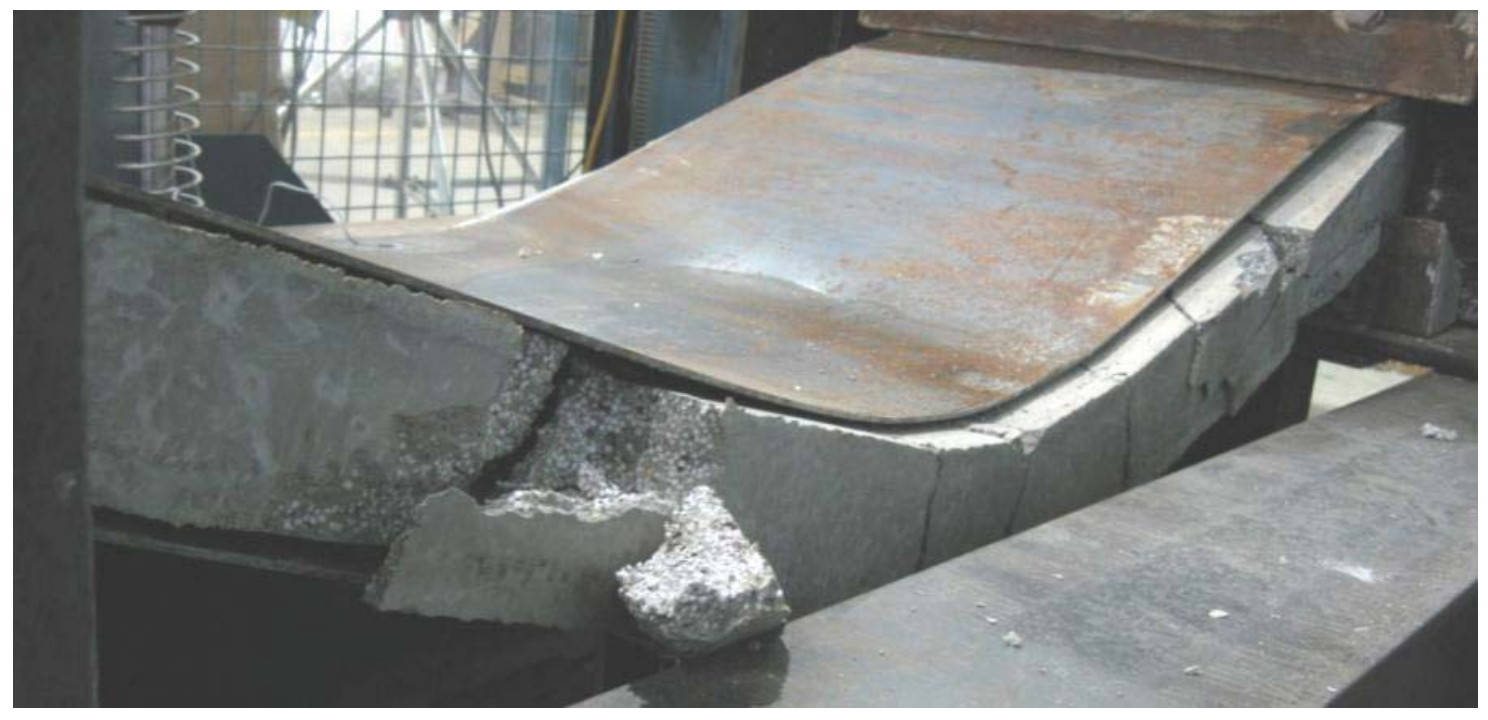

(c)

620 Figure 6: Damage of the concrete core of the Control panel after the impact test: (a)

Control panel, (b) Reinforced core panel, (c) Lightweight concrete core panel. 


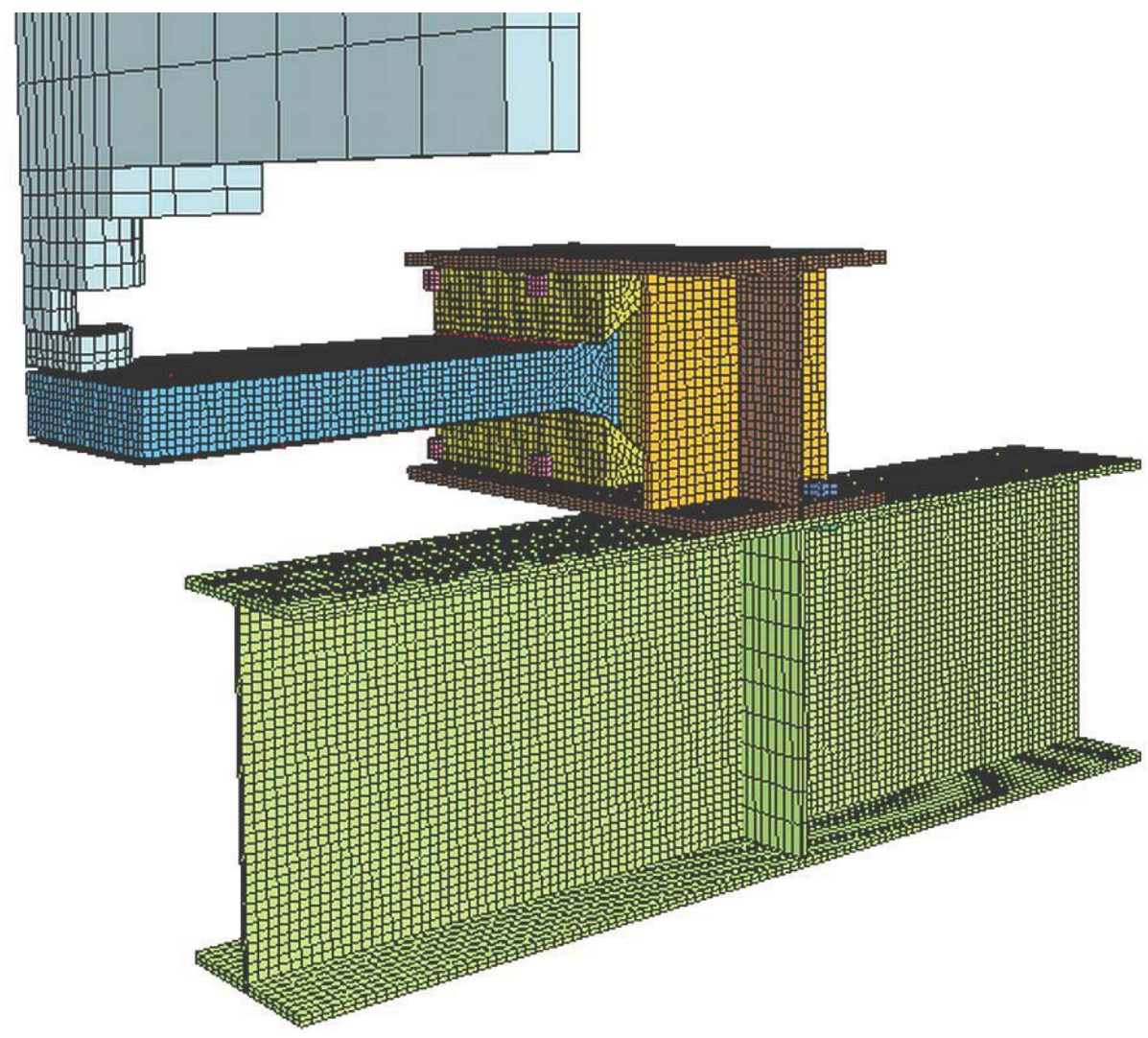

Figure 7: Numerical model of the experimental setup for axially restrained SCS sandwich panels using an instrumented impact testing system. 


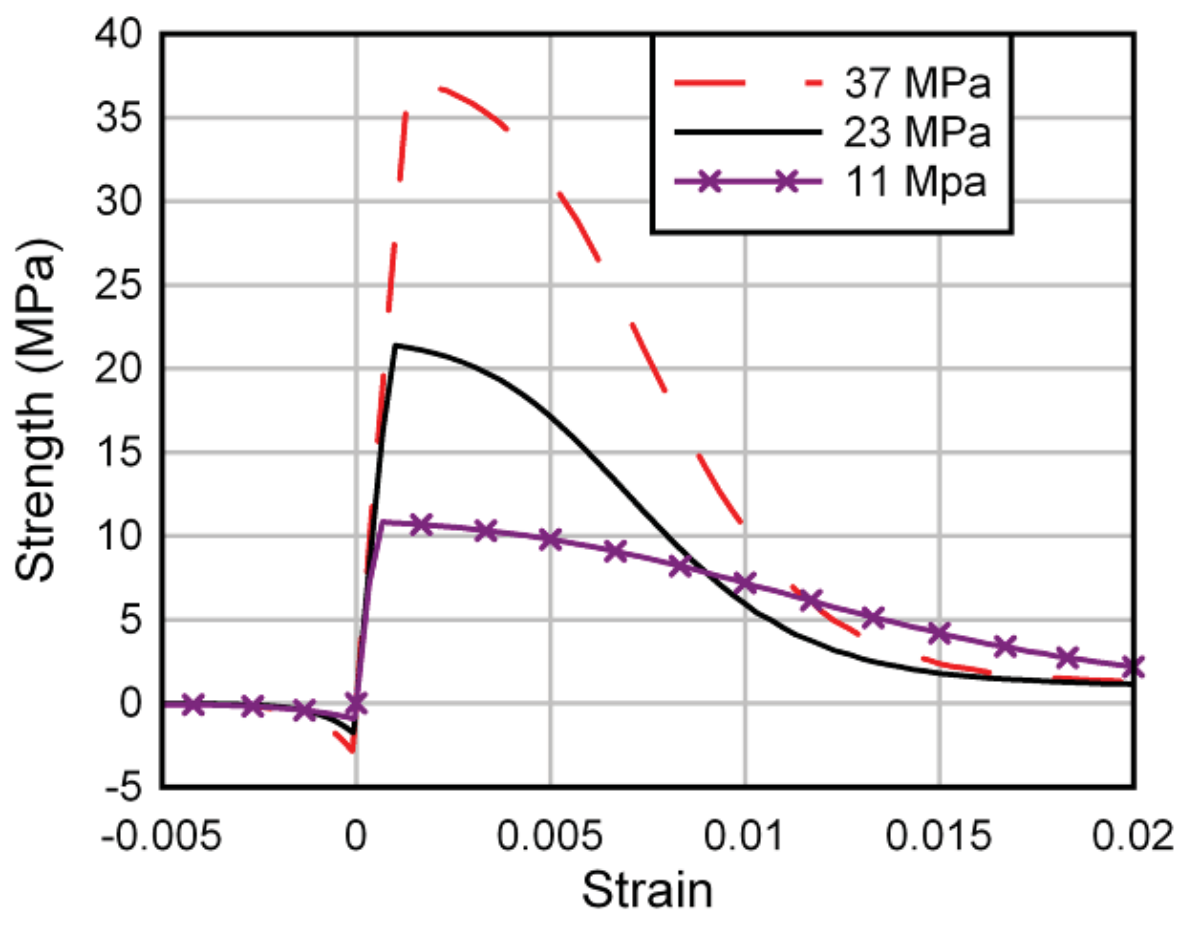

Figure 8: Stress-strain relationships numerically generated for concrete infill.
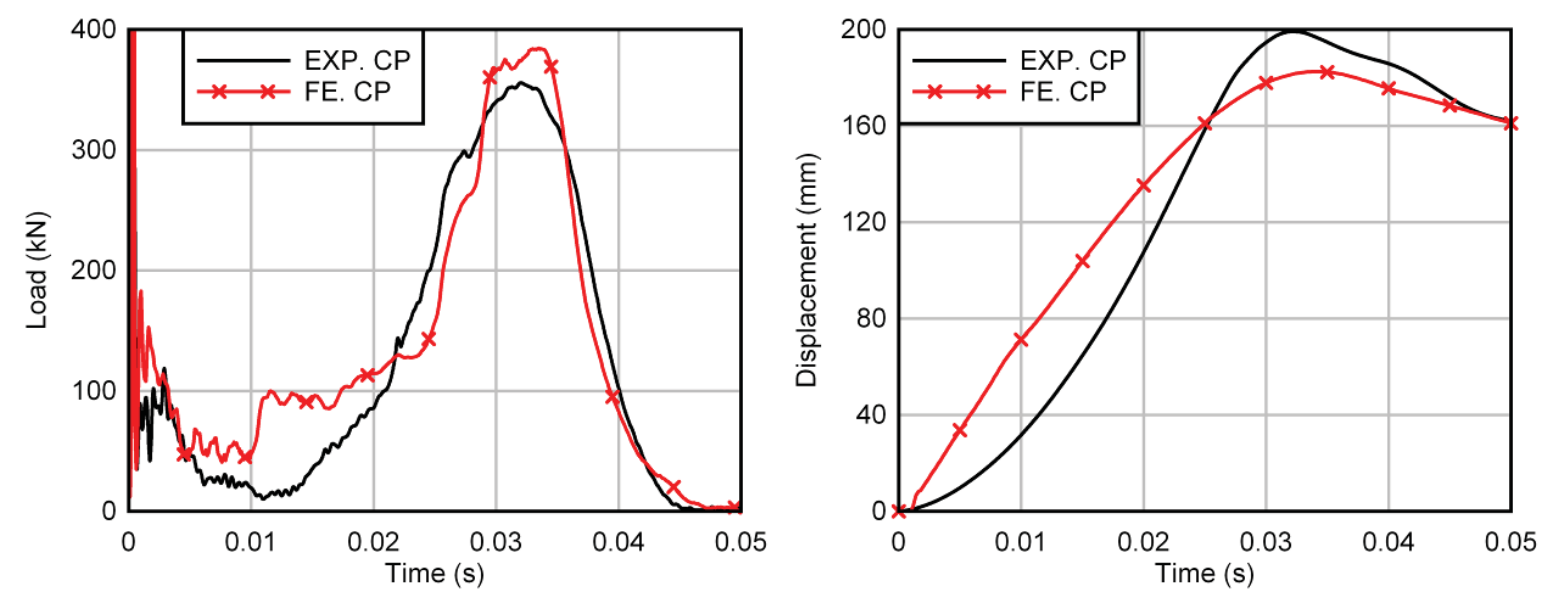

Figure 9: A comparison between experimental and predicted results for the Control panel (a) load time histories, (b) displacement time histories. 

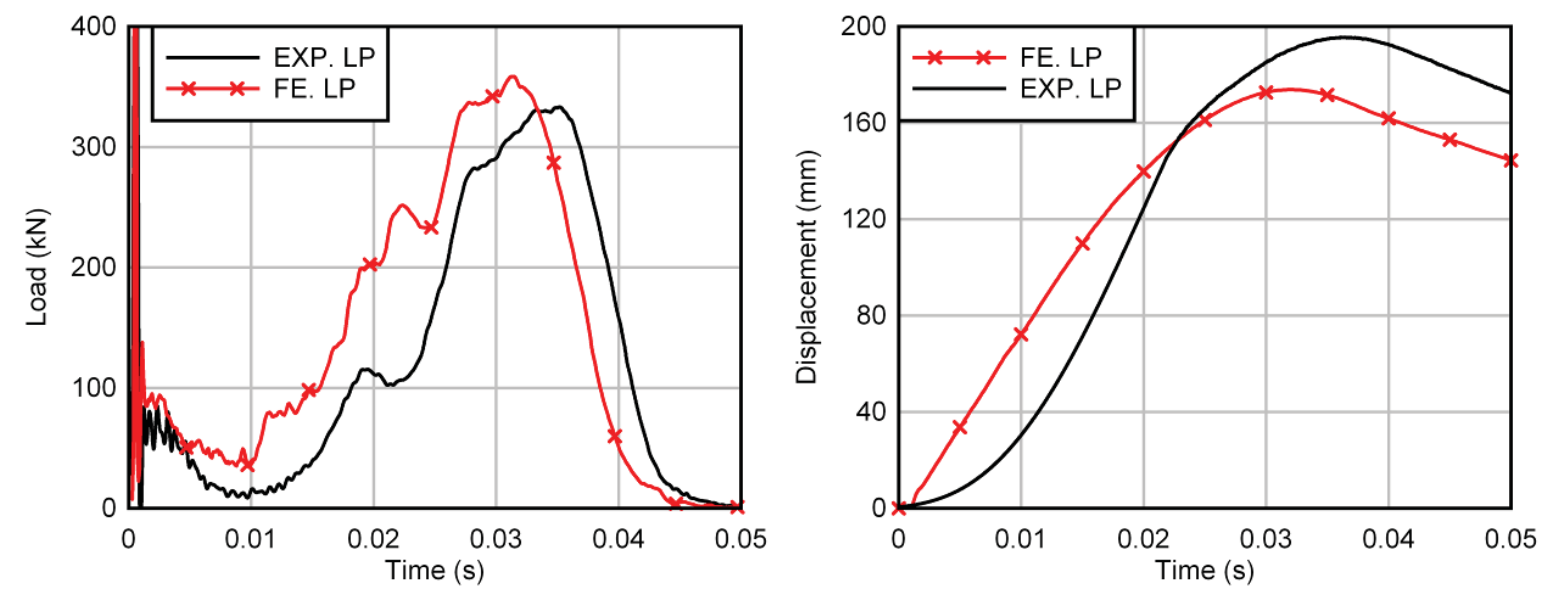

Figure 10: A comparison between experimental and predicted results for the Lightweight core panel (a) load time histories, (b) displacement time histories.
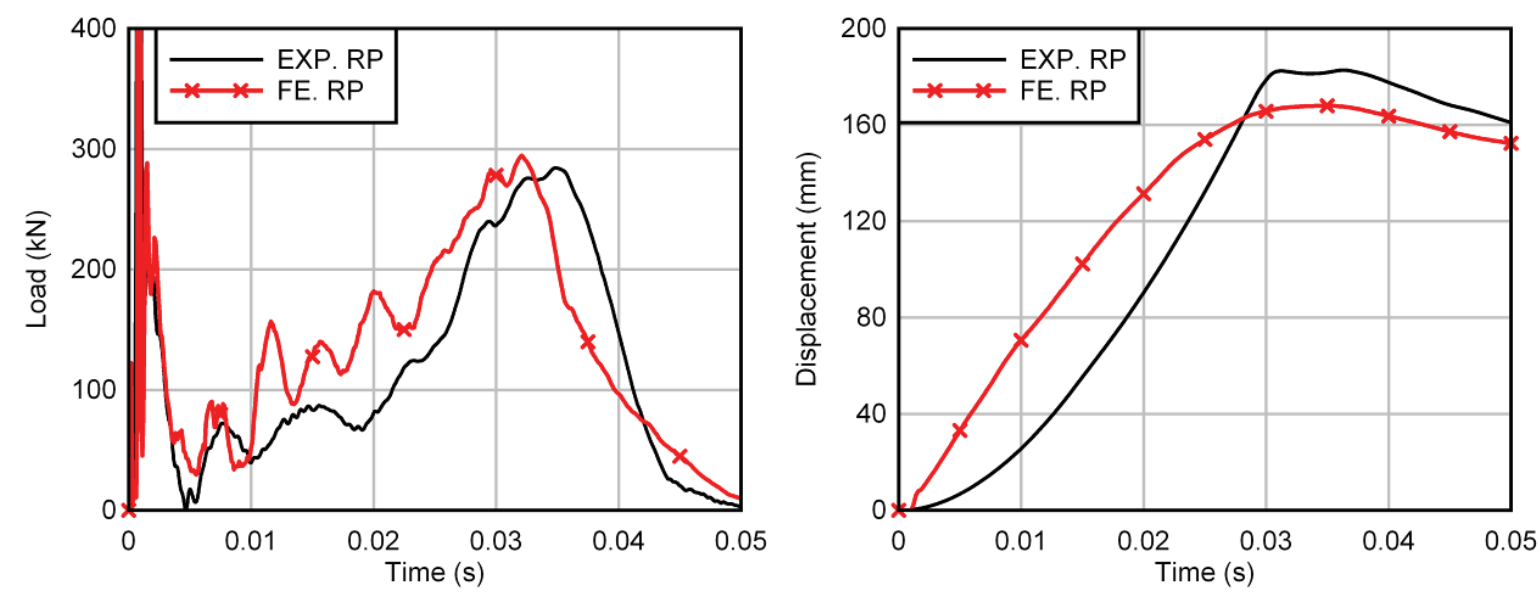

Figure 11: A comparison between experimental and predicted results for the Reinforced core panel (a) load time histories, (b) displacement time histories. 

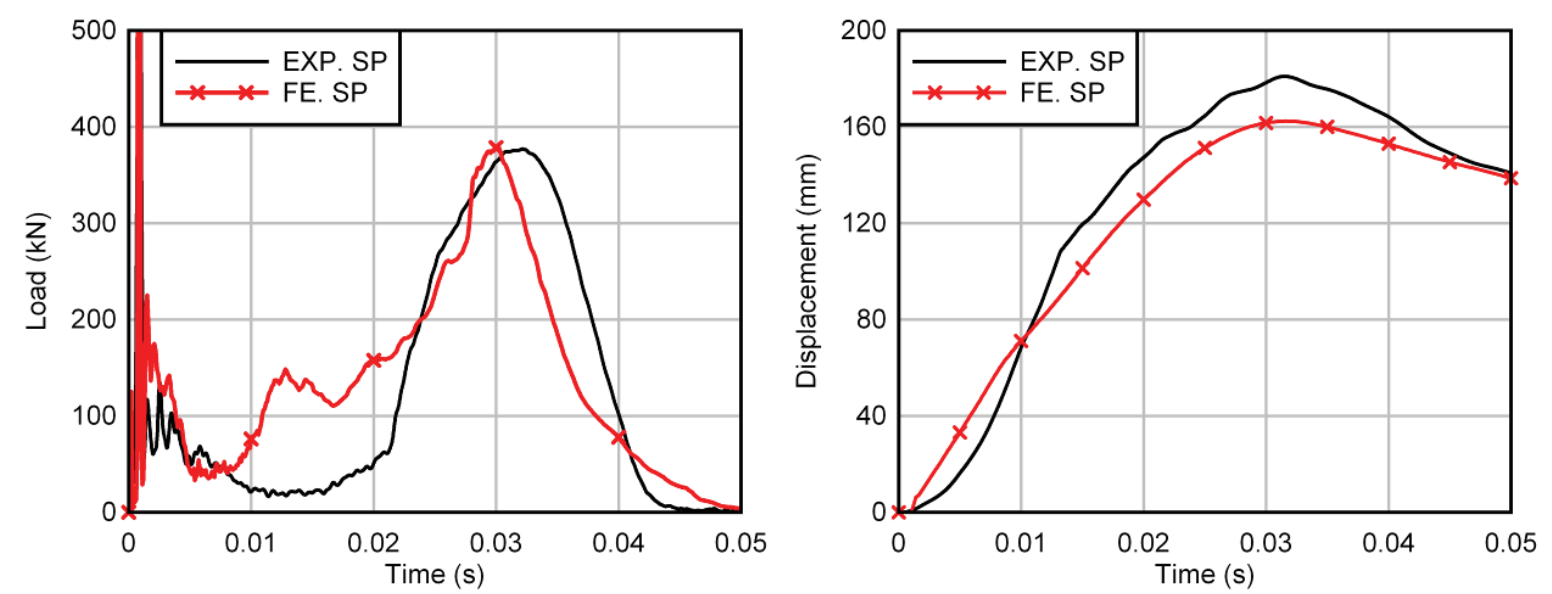

Figure 12: A comparison between experimental and predicted results for the Stainless steel panel (a) load time histories, (b) displacement time histories.

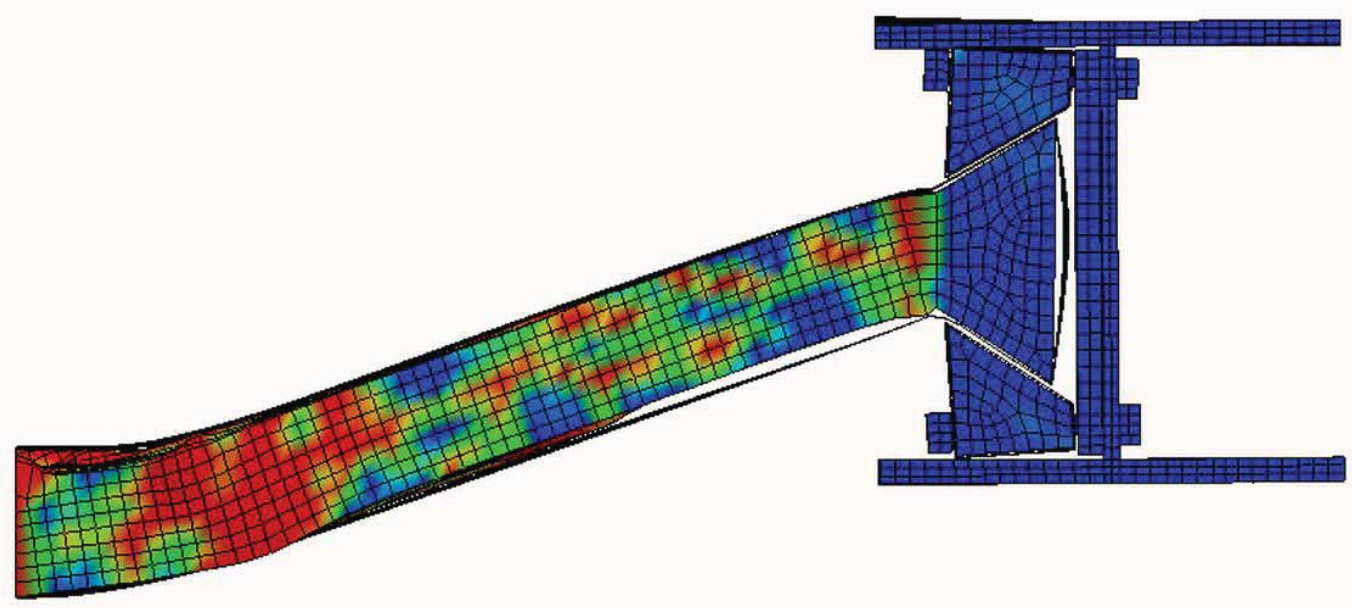

Fringe Levels

$9.990 \mathrm{e}-01$

$8.991 \mathrm{e}-01$

$7.992 \mathrm{e}-01$ $6.993 \mathrm{e}-01$ $5.994 \mathrm{e}-01$ $4.995 \mathrm{e}-01$ $3.996 \mathrm{e}-01$ $2.997 \mathrm{e}-01$ $1.998 \mathrm{e}-01$ $9.990 \mathrm{e}-02$ $0.000 \mathrm{e}+00$

Figure 13: Damage contour plot for the concrete core of the FE model for the Control panel (in the fringe bar: 0.0 - no damage; 1.0 - severe damage). 


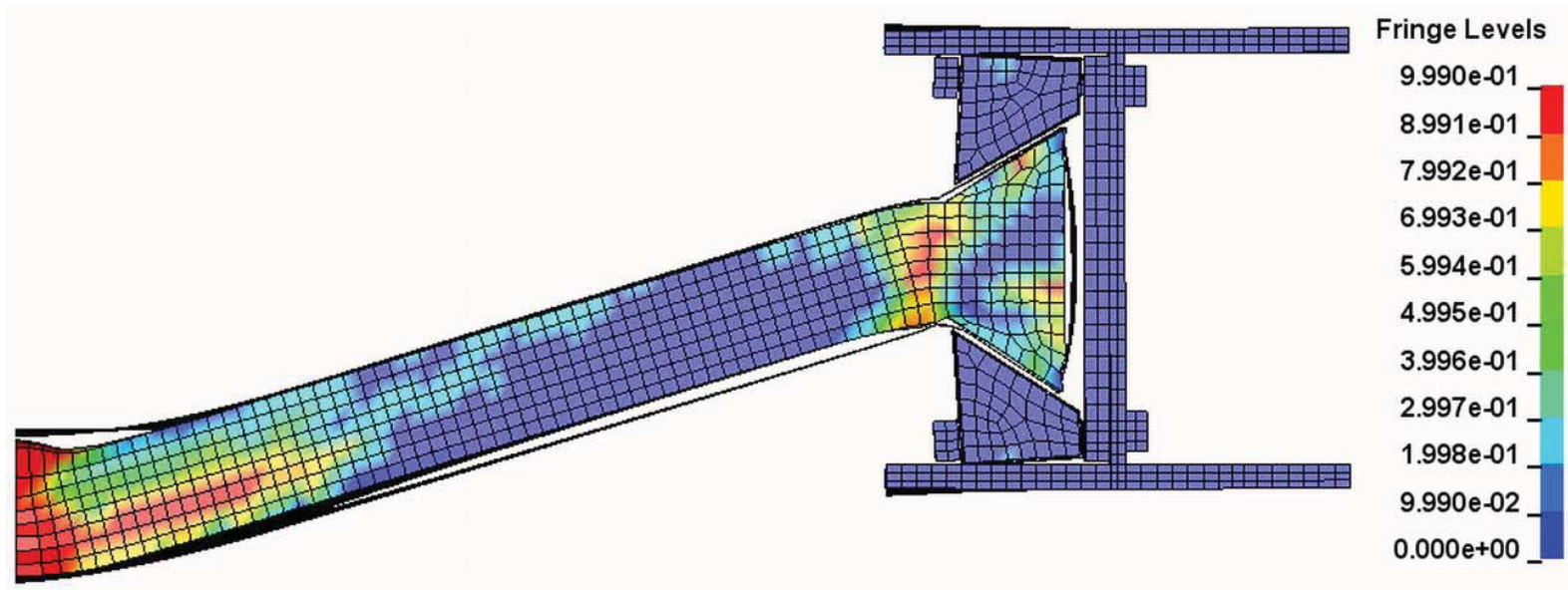

645 Figure 14: Damage contour plot for the concrete core for the FE model of the Reinforced core panel (in the fringe bar: 0.0 - no damage; 1.0 - severe damage).

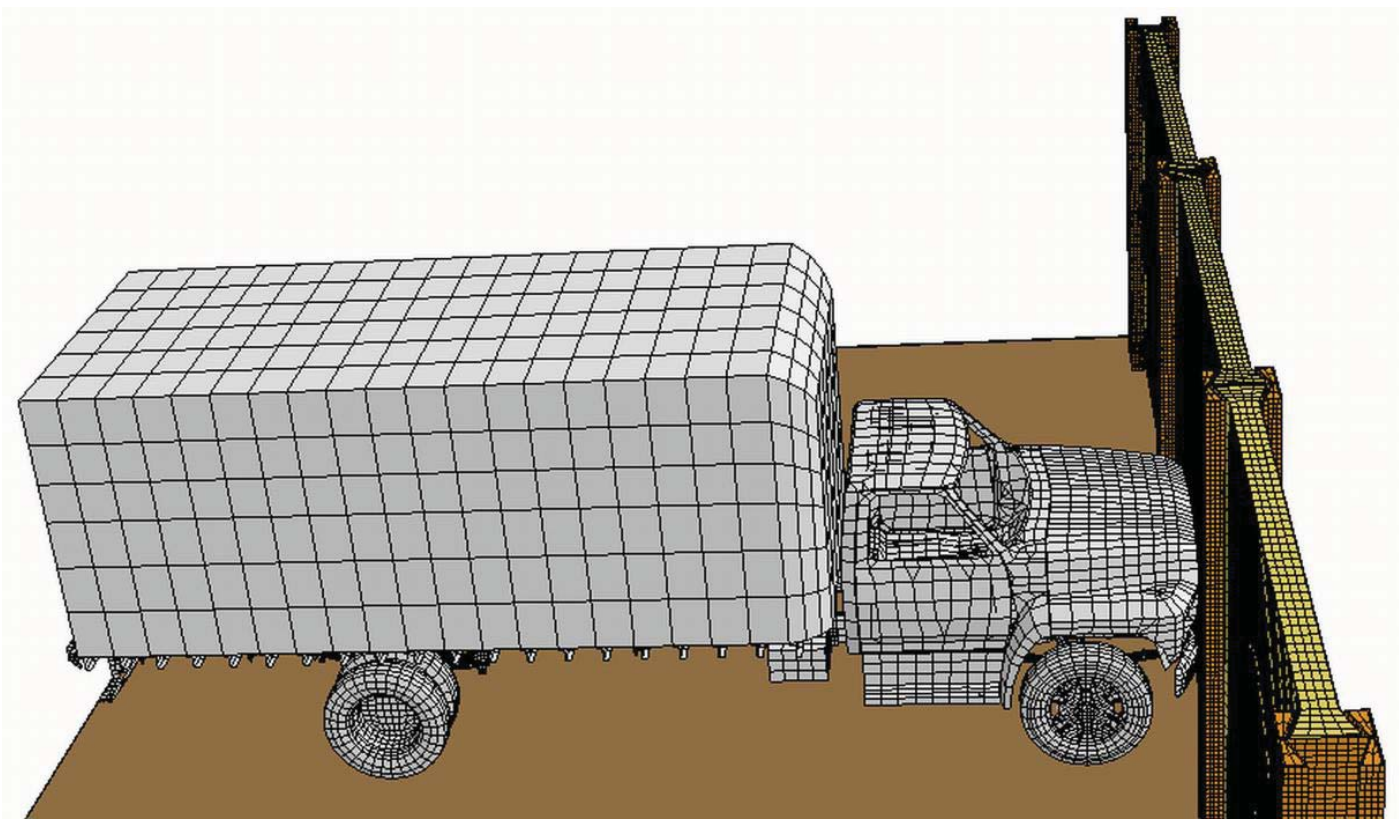

Figure 15: FE model of the full scale barrier subjected to vehicle impact by the Ford single unit truck. 

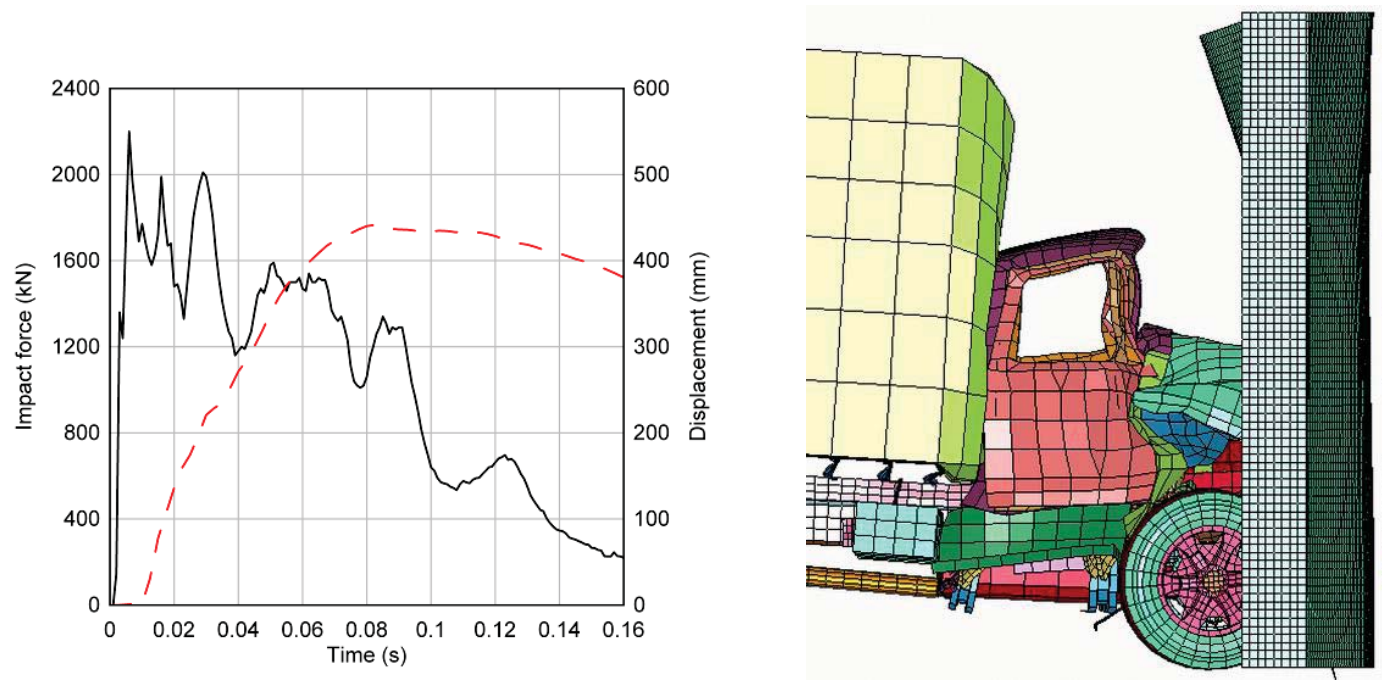

Figure 16: The simulation results (a) time histories of impact load and mid-height displacement for the barrier, (b) crashing deformation of the impacting truck.

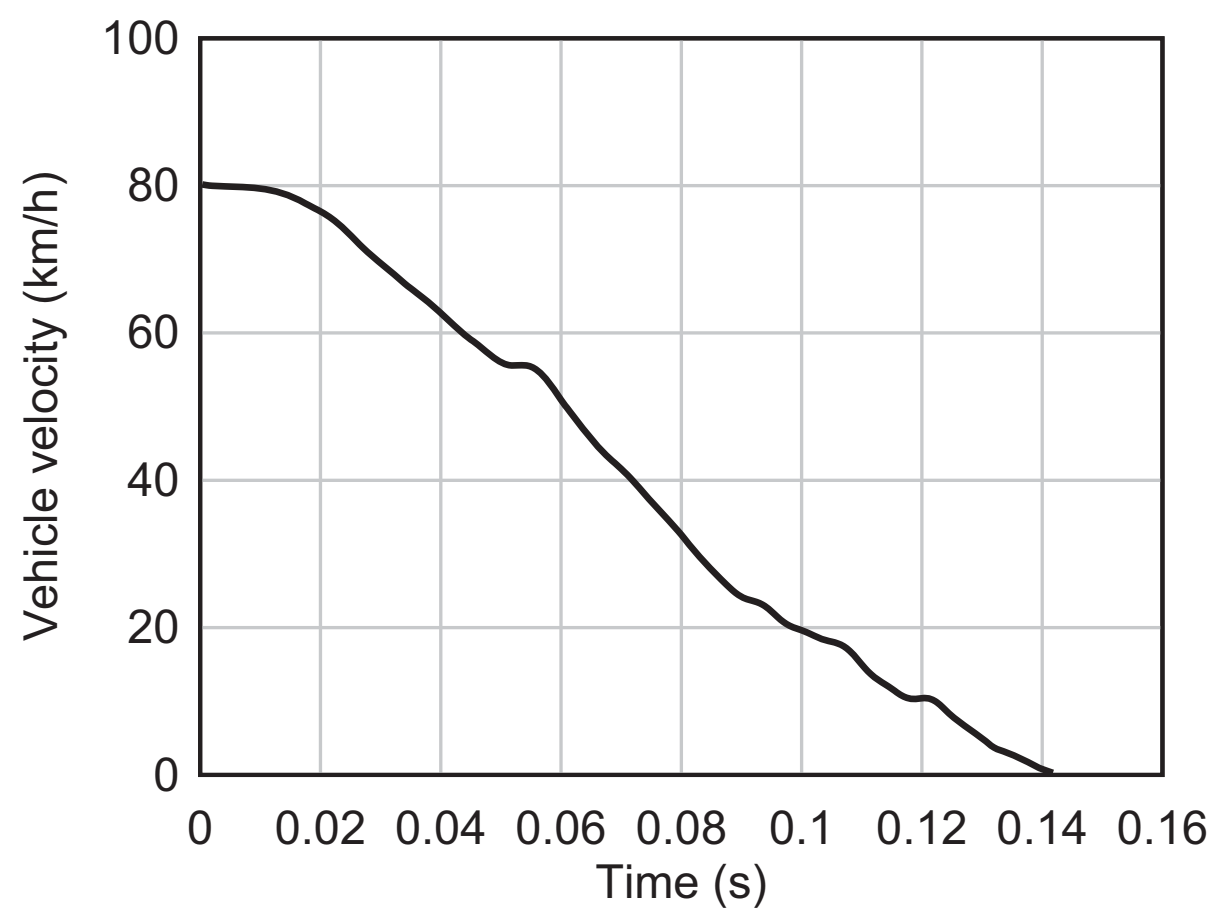

Figure 17: Time history of truck velocity 

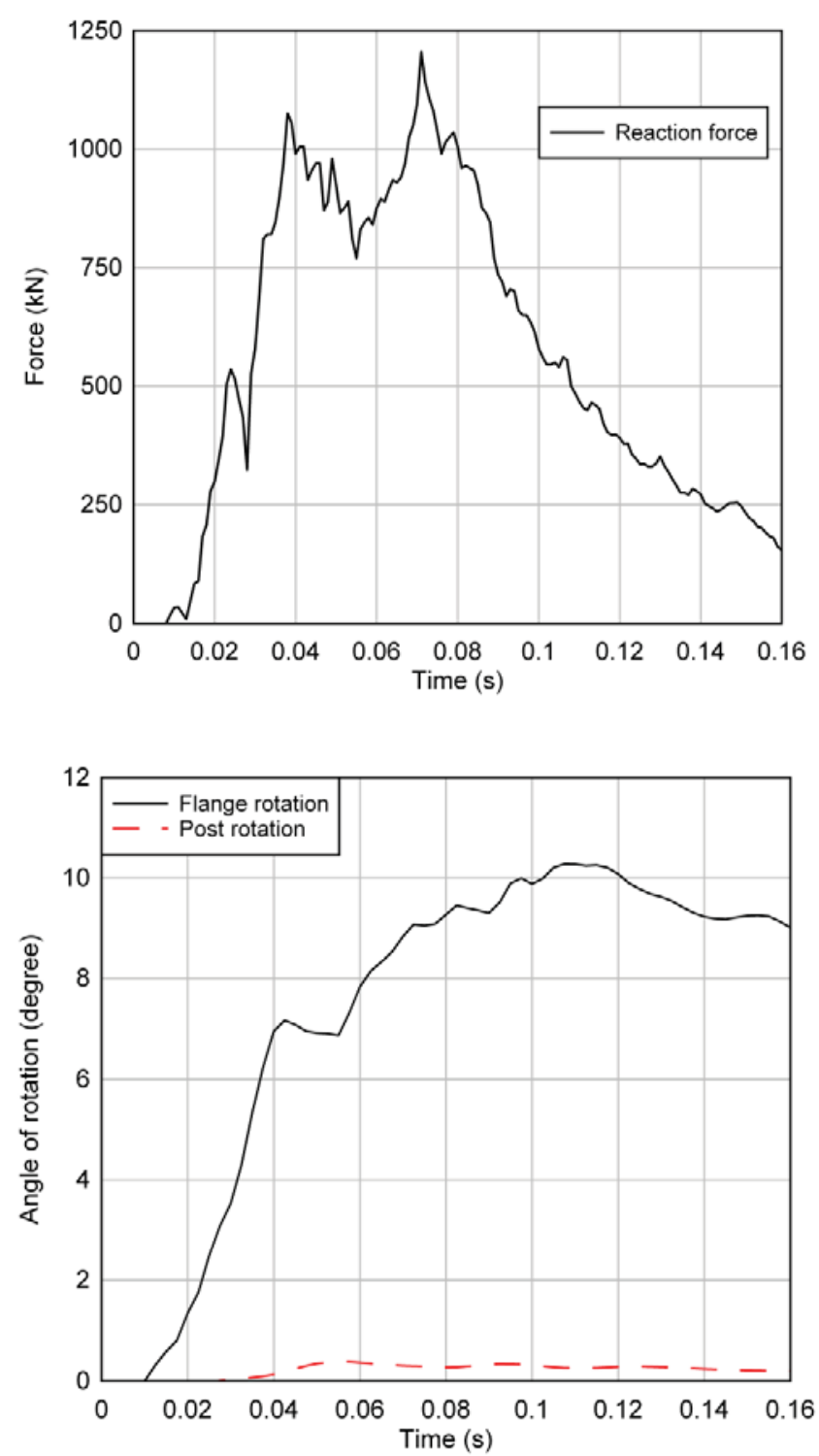

Figure 18: The simulation results (a) time history of the panel reaction force acting on the post, (b) time history of plastic rotation of the post flange. 

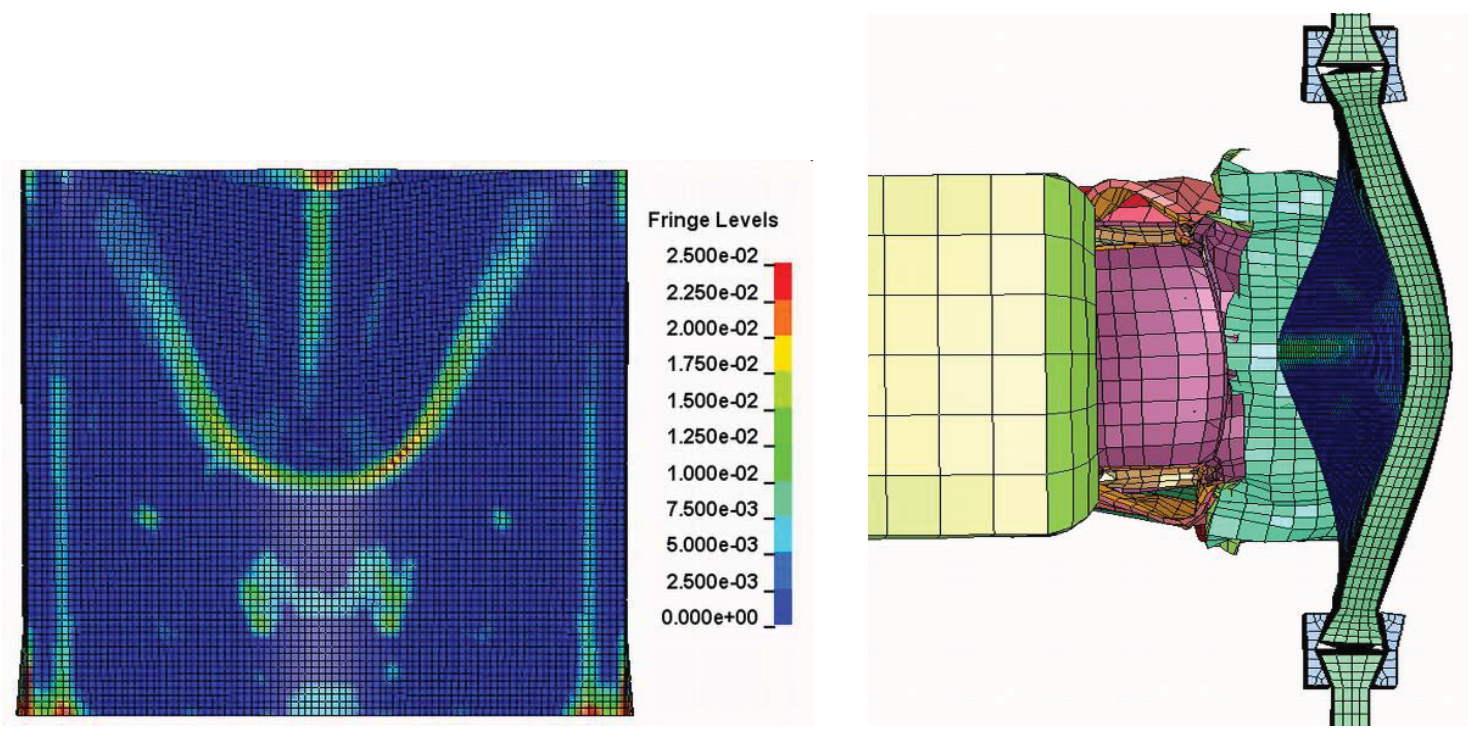

Figure 19: (a) Contour plot of plastic strain for the front faceplate of the panel, (b) deformations of the front and rear steel faceplates (view from the top).

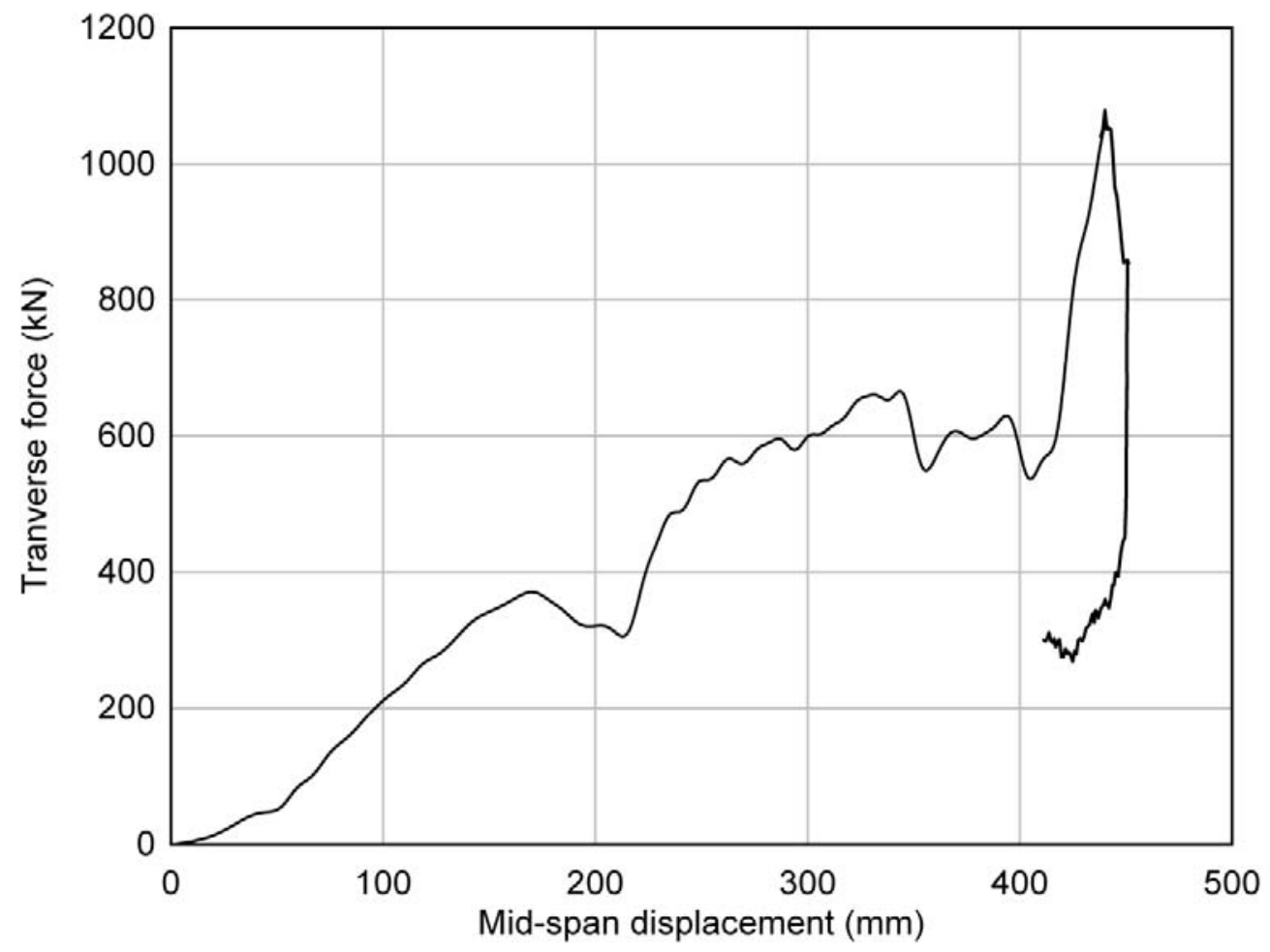

665 Figure 20: Tensile membrane resistance provided by the steel rear faceplate. 